\title{
Long-lived halocarbon trends and budgets from atmospheric chemistry modelling constrained with measurements in polar firn
}

\author{
P. Martinerie ${ }^{1}$, E. Nourtier-Mazauric ${ }^{1}$, J.-M. Barnola ${ }^{1}$, W. T. Sturges ${ }^{2}$, D. R. Worton ${ }^{2, *}$, E. Atlas ${ }^{3}$, L. K. Gohar ${ }^{4, * *}$, \\ K. P. Shine ${ }^{4}$, and G. P. Brasseur ${ }^{5}$ \\ ${ }^{1}$ Laboratoire de Glaciologie et Géophysique de l'Environnement (UMR CNRS/INSU 5183), CNRS, Université Joseph \\ Fourier-Grenoble, BP 96, 38402 Saint Martin d'Hères, France \\ ${ }^{2}$ School of Environmental Sciences, University of East Anglia, Norwich, NR4 7TJ, UK \\ ${ }^{3}$ Rosenstiel School of Marine and Atmospheric Science, University of Miami, Miami, FL 33149, USA \\ ${ }^{4}$ Department of Meteorology, University of Reading, Reading RG6 6BB, UK \\ ${ }^{5}$ National Center for Atmospheric Research, Boulder, CO 80307-3000, USA \\ "now at: Department of Environmental Science, Policy and Management, University of California, Berkeley, \\ CA 94720-3110, USA \\ ** now at: Met Office Hadley Centre, FitzRoy Road, Exeter. EX1 3PB, UK
}

Received: 14 November 2008 - Published in Atmos. Chem. Phys. Discuss.: 13 January 2009

Revised: 5 May 2009 - Accepted: 28 May 2009 - Published: 17 June 2009

\begin{abstract}
The budgets of seven halogenated gases (CFC$11, \mathrm{CFC}-12$, CFC-113, CFC-114, CFC-115, $\mathrm{CCl}_{4}$ and $\mathrm{SF}_{6}$ ) are studied by comparing measurements in polar firn air from two Arctic and three Antarctic sites, and simulation results of two numerical models: a 2-D atmospheric chemistry model and a 1-D firn diffusion model. The first one is used to calculate atmospheric concentrations from emission trends based on industrial inventories; the calculated concentration trends are used by the second one to produce depth concentration profiles in the firn. The 2-D atmospheric model is validated in the boundary layer by comparison with atmospheric station measurements, and vertically for CFC- 12 by comparison with balloon and FTIR measurements. Firn air measurements provide constraints on historical atmospheric concentrations over the last century. Age distributions in the firn are discussed using a Green function approach. Finally, our results are used as input to a radiative model in order to evaluate the radiative forcing of our target gases. Multi-species and multi-site firn air studies allow to better constrain atmospheric trends. The low concentrations of all studied gases at the bottom of the firn, and their consistency with our model results confirm that their natural sources are small. Our results indicate that the emissions, sinks and trends of CFC-11, CFC-12, CFC-113, CFC-115 and $\mathrm{SF}_{6}$ are well constrained, whereas it is not the case for CFC-114 and $\mathrm{CCl}_{4}$. Signif-
\end{abstract}

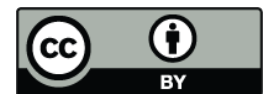

Correspondence to: $\mathrm{P}$. Martinerie (patricia@lgge.obs.ujf-grenoble.fr) icant emission-dependent changes in the lifetimes of halocarbons destroyed in the stratosphere were obtained. Those result from the time needed for their transport from the surface where they are emitted to the stratosphere where they are destroyed. Efforts should be made to update and reduce the large uncertainties on CFC lifetimes.

\section{Introduction}

This study presents a trend and budget analysis of seven halogenated gases: CFC-11 $\left(\mathrm{CCl}_{3} \mathrm{~F}\right), \mathrm{CFC}-12\left(\mathrm{CCl}_{2} \mathrm{~F}_{2}\right)$, CFC-113 $\left(\mathrm{CCl}_{2} \mathrm{FCClF}_{2}\right), \mathrm{CFC}-114\left(\mathrm{CClF}_{2} \mathrm{CClF}_{2}\right), \mathrm{CFC}-115$ $\left(\mathrm{CClF}_{2} \mathrm{CF}_{3}\right), \mathrm{CCl}_{4}$ and $\mathrm{SF}_{6}$. These species are greenhouse gases (GHGs) and a new evaluation of their radiative impact is provided. Chlorofluorocarbons (CFCs) and $\mathrm{CCl}_{4}$ are also ozone-depleting substances. Our target gases have very long lifetimes because they are destroyed above the troposphere. They are presumed to be predominantly, if not totally anthropogenic (WMO, 2007).

Originally developed in 1930 as refrigerants, CFCs have also been used as aerosol propellants, foam blowing agents, and cleaning solvents (especially in the electronics industry). Carbon tetrachloride $\left(\mathrm{CCl}_{4}\right)$ was first used from the early 1900s to the mid 1960s as a fire extinguishing and a degreasing agent. More recently, it has been used in many other industrial processes. Its atmospheric emissions are thought to arise mainly from its use in the production of CFC-11 and

Published by Copernicus Publications on behalf of the European Geosciences Union. 


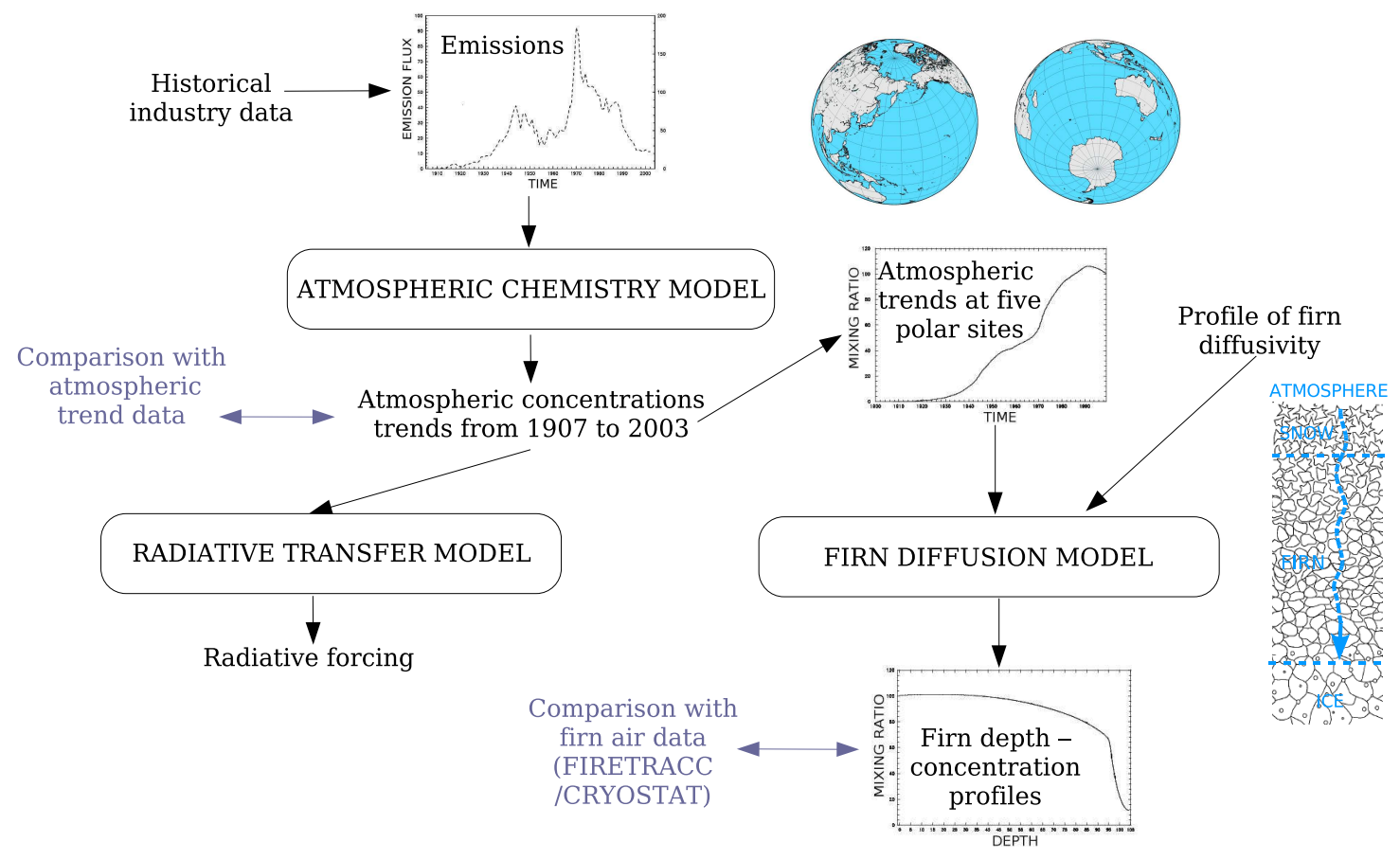

Fig. 1. Combined use of 3 numerical models.

CFC-12. First introduced in the 1960's, sulphur hexafluoride $\left(\mathrm{SF}_{6}\right)$ became widespread in the 1980's. It is used mostly as an insulator in electrical transformers and in magnesium production. Targeted by the Montreal protocol, CFC emissions started to decrease in 1998 and are now close to zero (AFEAS, 2007). Also controlled by the Montreal Protocol, $\mathrm{CCl}_{4}$ emissions decrease started earlier: 1972 (Simmonds et al., 1998), whereas $\mathrm{SF}_{6}$ emissions (controlled under the Kyoto Protocol) likely decreased temporarily around 19971999 before increasing again (Maiss and Brenninkmeijer, 2000; Smythe, 2004).

While CFCs and $\mathrm{CCl}_{4}$ are nearly inert in the troposphere, they are destroyed in the stratosphere by UV photolysis and oxidation with $\mathrm{O}\left({ }^{1} \mathrm{D}\right)$ radicals. However, $\mathrm{CCl}_{4}$ may have two important surface sinks: oceanic (Yvon-Lewis and Butler, 2002) and soil (Happell and Roche, 2003) losses could play a major role in the destruction and lifetime of $\mathrm{CCl}_{4}$ (WMO, 2007). Sulphur hexafluoride has a very long lifetime (3200 years) as it is destroyed only in the mesosphere, through photolysis and ion reactions (Ravishankara et al., 1993; WMO, 2007).

Whereas all the studied gases are emitted mainly in the Northern Hemisphere, their concentrations are similar in both hemispheres because their very long lifetimes allow for their mixing in the whole atmosphere. Such long lifetimes also explain the important time lag between the emission decrease of $\mathrm{CFCs}$ and $\mathrm{CCl}_{4}$, and the decrease of their concentrations. Air measurements performed at ground stations in both hemispheres provided atmospheric trends of most of the studied gases for the last thirty years at best (e.g. Elkins et al., 1998 and Prinn et al., 2000 for the major ESRL (Earth System Research Laboratory, previously called CMDL) and AGAGE (Advanced Global Atmospheric Gases Experiment, previously called GAGE and ALE) networks. These records can be extended back to the earlier part of the 20th century by using measurements in polar firn.

Trace gases diffuse slowly from the atmosphere through the open channels of polar firn down to the ice forming zone, where they are trapped in air bubbles. The time scale of this process is of the order of decades to a century. It depends primarily on the tortuosity of the open porosity at the considered site, and on the time trend of the gas concentration at the surface, which drives the concentration gradient (and thus diffusion speed) between the top and the bottom of the firn. Pumping firn air at different depths allows the extraction of relatively large amounts of air which permits the measurements of low concentration gases (Schwander et al., 1993). Several studies have used firn diffusion models to infer our target gases concentration history from firn air measurements (Schwander et al., 1993; Butler et al., 1999; Sturges et al., 2000; Sturrock et al., 2002; Trudinger et al., 2002). The originality of our approach is to use an atmospheric chemistry model in order to constrain the concentration trends used as input to the firn diffusion model.

Figure 1 illustrates our combined use of three numerical models in order to interpret firn air data in terms of 
species trends, budgets and radiative forcings. Historical emission data are used to constrain a 2-D model of tropospheric and stratospheric chemistry run on the century time scale (Brasseur et al., 1990; Martinerie et al., 1995). The model calculates the transport and chemical destruction of trace gases, and the balance of these processes controls the species atmospheric concentration fields. Model results are validated by comparison with atmospheric data sets: surface trends, total column, and balloon-based measurements.

The predicted atmospheric concentration trends are used as input to a direct model of gas diffusion in interstitial air of polar firn (Rommelaere et al., 1997), in order to be compared with trace gas concentrations in firn measured within the FIRETRACC and CRYOSTAT EC projects. Measurements were made at five Arctic and Antarctic sites: Devon Island and North Greenland Ice Coring Project (North GRIP) in the Northern Hemisphere, and Dronning Maud Land, Dome Concordia and Berkner Island in the Southern Hemisphere. The firn diffusion model has to be constrained with a sitespecific effective depth-diffusivity profile. It is calculated using both the known long term atmospheric trend and concentrations in firn air of a reference gas (such as $\mathrm{CO}_{2}$ or $\mathrm{CH}_{4}$ ) to constrain an inverse version of our firn model (Fabre et al., 2000; Rommelaere et al., 1997).

The combined use of an atmospheric chemistry model and a firn diffusion model allows the discussion of the model/data comparison in terms of budget understanding for our target species. The uncertainties vary largely from one species to another, and we discuss the impact of different factors such as emissions, lifetime, measurement calibration, and diffusivity in polar firn.

The atmospheric chemistry model based halocarbon concentrations are also used for calculating a time history of radiative forcing for all studied gases.

This manuscript is organized as follows. Section 2 describes the firn diffusion and atmospheric chemistry models. Sections 3 and 5 present their validation. The trace gas measurements in firn air (Sect. 4) are introduced just before the firn model validation (Sect. 5). In Sect. 6, we discuss our understanding of trace gas ages in the firn (Sect. 6.1), and our target gas trends (Sect. 6.2), lifetimes (Sect. 6.3) and budgets (Sect. 6.4). Section 6.5 deals with their radiative impact.

$$
\text { The supplementary material (http:// }
$$
www.atmos-chem-phys.net/9/3911/2009/ acp-9-3911-2009-supplement.pdf) presents firn diffusivities and additional firn age data discussed in terms more firn-oriented than atmosphere-oriented. It also contains additional chemistry model results which are presented below only for selected species.

\section{Numerical models}

\subsection{The atmospheric chemistry model}

Simulations of atmospheric chemistry are performed with a global zonally averaged model with $5^{\circ}$ latitude bands from $85^{\circ} \mathrm{S}$ to $85^{\circ} \mathrm{N}$ and $1 \mathrm{~km}$ vertical layers from the Earth surface to $85 \mathrm{~km}$ (Brasseur et al., 1990; Martinerie et al., 1995). The time step is 15 days, allowing for 100 years simulations to be performed in a few hours on a personal computer (PC). Radiation, transport and chemistry of the middle atmosphere are fully coupled. Mean monthly climatological winds and temperatures (Randel, 1987) are imposed in the troposphere. The model includes an improved version of the NCAR CCM1 radiative code (Wang et al., 1991). Chemistry comprises $\mathrm{HO}_{\mathrm{x}}$, $\mathrm{NO}_{\mathrm{y}}, \mathrm{CH}_{4}, \mathrm{CO}, \mathrm{PAN}, \mathrm{Cl}_{\mathrm{y}}$, and $\mathrm{Br}_{\mathrm{y}}$, represented by 56 long and 28 short lived species. $\mathrm{SF}_{6}$ is destroyed at very high altitudes and longer time scales than our 100 years simulations. Thus its lifetime is not calculated but imposed as 3200 years (WMO, 2007).

A new photochemistry code has been coupled to the model: TUV3.9 (Madronich, 1993, Madronich, personal communication, 1998). Its spectral grid includes 183 intervals between 116.3 and $735 \mathrm{~nm}$. The chemical and photochemical reaction rates were updated to take into account recent evaluations (Sander et al., 2006; IUPAC, 2006).

The model ability to simulate large scale meridional gradients and long term trends has been tested using ${ }^{85} \mathrm{Kr}$. The model was constrained by emission data since the beginning of ${ }^{85} \mathrm{Kr}$ production (1945). Calculated concentrations were compared to observations (the data used as well as the approach are described in Jacob et al., 1987; Zimmermann et al., 1989; Levin and Hesshaimer, 1996). Although the low spatial and time resolution of the model does not allow to achieve similar precision as the above 3-D models, a satisfactory representation of ${ }^{85} \mathrm{Kr}$ trend and meridional gradient is obtained.

The estimates of halocarbon historical anthropogenic emissions are based on production/sales data provided by chemical manufacturers, and emission functions. These functions represent the timing and rate of halocarbon emissions to the atmosphere, and primarily depend on halocarbon usage categories. For example, emissions from open cell foams will be much faster than those from closed-circuit refrigeration. All major manufacturers from developed countries report their CFC productions. Yearly updated emission data were derived from these data (AFEAS, 2007). However, companies responding to AFEAS represent a diminishing fraction (less than 16\% in 2004) of global CFC sales, thus only global production is reported for 2004 and there will be no data in the future. Production and emission data from non reporting countries (mainly from Eastern Europe and Asia) are less precise and updated on a less regular basis.

For CFCs (CFC-11, CFC-12, CFC-113, CFC-114, CFC$115)$, the model was constrained with emissions reported to 
AFEAS (2007). Recent estimates of non-reported emissions were used when available (CFC-11: McCulloch et al., 2001; CFC-12 and CFC-113: McCulloch et al., 2003). To our knowledge, no estimate of non-reported emissions is available for CFC-114 and CFC-115, thus we neglect them in the first instance. For $\mathrm{CCl}_{4}$, emission data from Simmonds et al. (1998) were used until 1995, and extrapolated using the same methodology of scaling to CFC production. This gives more reliable results than a simple extrapolation of $\mathrm{CCl}_{4}$ emission data. $\mathrm{SF}_{6}$ emissions were initially taken from Maiss and Brenninkmeijer $(1998,2000)$. However this resulted in an overestimation of the slope of the $\mathrm{SF}_{6}$ trend around 1998-2002. Thus the more recent estimate from the EDGAR database (V3.2 and V3.2 FT2000, EDGAR, 2007) has been used. This dataset covers the 1949-1995 period and year 2000, it was completed using Smythe (2004). For all compounds, the meridional distribution of the emissions was taken from the EDGAR (2007) database: EDGAR V2.0 for all CFCs (data for the year 1986), and EDGAR v3.2 FT2000 (year 1990) for $\mathrm{SF}_{6}$. In the absence of data, the meridional distribution of $\mathrm{CCl}_{4}$ emissions was assumed to be the same as for CFC-12. The surface ocean is not represented in the model, and the meridional distribution of $\mathrm{CCl}_{4}$ soil sink still has to be quantified. Besides, WMO (2007) states that the $\mathrm{CCl}_{4}$ ocean and soil sinks are difficult to reconcile with its concentration records, thus these sinks were not taken into account in our model. Their potential effect is discussed in Sect. 6.4.

As in Martinerie et al. (1995), the model boundary conditions are imposed concentrations at the ground for $\mathrm{CO}_{2}, \mathrm{CH}_{4}$ and $\mathrm{N}_{2} \mathrm{O}$ and emission fluxes for other major source gases, which control the oxidation capacity of the troposphere but have a minor influence on the stratosphere. The effect of the trends in $\mathrm{CO}_{2}, \mathrm{CH}_{4}$ and $\mathrm{N}_{2} \mathrm{O}$ on halocarbon concentrations was evaluated by comparison with a test simulation constrained with the 3 major greenhouse gases having constant (1990) concentrations over the whole 100 years simulation. The induced change in our target species concentration trends is negligible (less than $0.2 \%$ ).

\subsection{The firn diffusion model}

A firn diffusion model is a dating tool, calculating trace gas depth-concentration profiles as a function of their atmospheric trends. Three depth zones are distinguished in our model (Rommelaere et al., 1997). In the upper part of the firn (a few meters), a "well mixed zone" can be defined. Due to mechanical (wind) and thermal mixing, it has the same composition as the above atmospheric air. Below, in the "transport zone", concentration gradients between the top and the bottom of the firn induce trace gas diffusion in firn air. Gravitational fractionation also occurs. For our target gases, which are heavier than air, gravitational fractionation leads to mixing ratios increased by $2.5 \%$ to $9 \%$ at the bottom of the firn, depending on the firn close-off depth and trace gas molecular mass. Trace gas diffusion and gravitational fractionation induce a trace gas flux in the firn which lead to vertical concentration gradients. At the bottom of the firn, namely the "close-off zone" or "lock in zone", densification leads to the formation of air bubbles. The ratio of open over closed porosity decreases rapidly with depth. The duration of the close-off process mainly depends on the snow accumulation rate, which moves the firn downward. Steeper depth-concentration gradients are observed in the lowest part of the firn where diffusion is very slow and open porosity decreases. The ice zone starts where porosity is totally closed. The air composition is then fixed, and the air bubbles are simply advected down with the ice. The most important processes occurring in the firn are trace gas diffusion and bubble close-off, which eliminates old air from the deepest part of the firn. Our firn model and the mathematical representation of the above processes are described in Rommelaere et al. (1997).

Several assumptions are made in our representation of trace gases transport in firn. The snow accumulation rate, temperature and firn structure at a given depth (characterized by porosity, density, tortuosity, etc...) are assumed to be independent of time. This is justified here because the studied period is short and climatically stable. Firn temperature is also considered as uniform and close to mean annual temperature. This is consistent with direct observations in polar firn below ten meters depth. Thermal diffusion is not taken into account; it would mainly affect the upper ten meters of the firn. Considering trace gas transport, all gases are assumed to verify ideal gas law. Molecules are assumed to collide with each other much more than with firn surface, because their mean free path is much smaller than the dimension of pores in firn. For the studied inert gases having low solubilities in water, gas exchanges through the surface of firn pores are neglected.

An essential parameter used to constrain firn diffusion models is the effective diffusivity-depth profile. It depends on the tortuosity of the open firn porosity. Direct measurements of trace gas diffusion coefficients in firn samples have been performed (Schwander et al., 1988; Fabre et al., 2000). These measurements are time consuming, thus relationships between diffusivity and porosity (or its inverse: density) have been used to extrapolate them to other sites (Schwander et al., 1993; Trudinger et al., 1997). In this study, effective diffusivity profiles are retrieved by inverse modelling of a trace gas having a well known atmospheric trend and a firn depth profile at the studied site (Fabre et al., 2000; Rommelaere et al., 1997). $\mathrm{CH}_{4}$ was used for diffusivity calculation at all sites except Dome C, where $\mathrm{CO}_{2}$ leads to better results around $95 \mathrm{~m}$ depth (see supplement http://www.atmos-chem-phys.net/9/3911/2009/ acp-9-3911-2009-supplement.pdf). We should note that the effective diffusivity is constrained to be an increasing function of open porosity, and therefore a decreasing function of depth. This does not allow to explicitly take into account the 

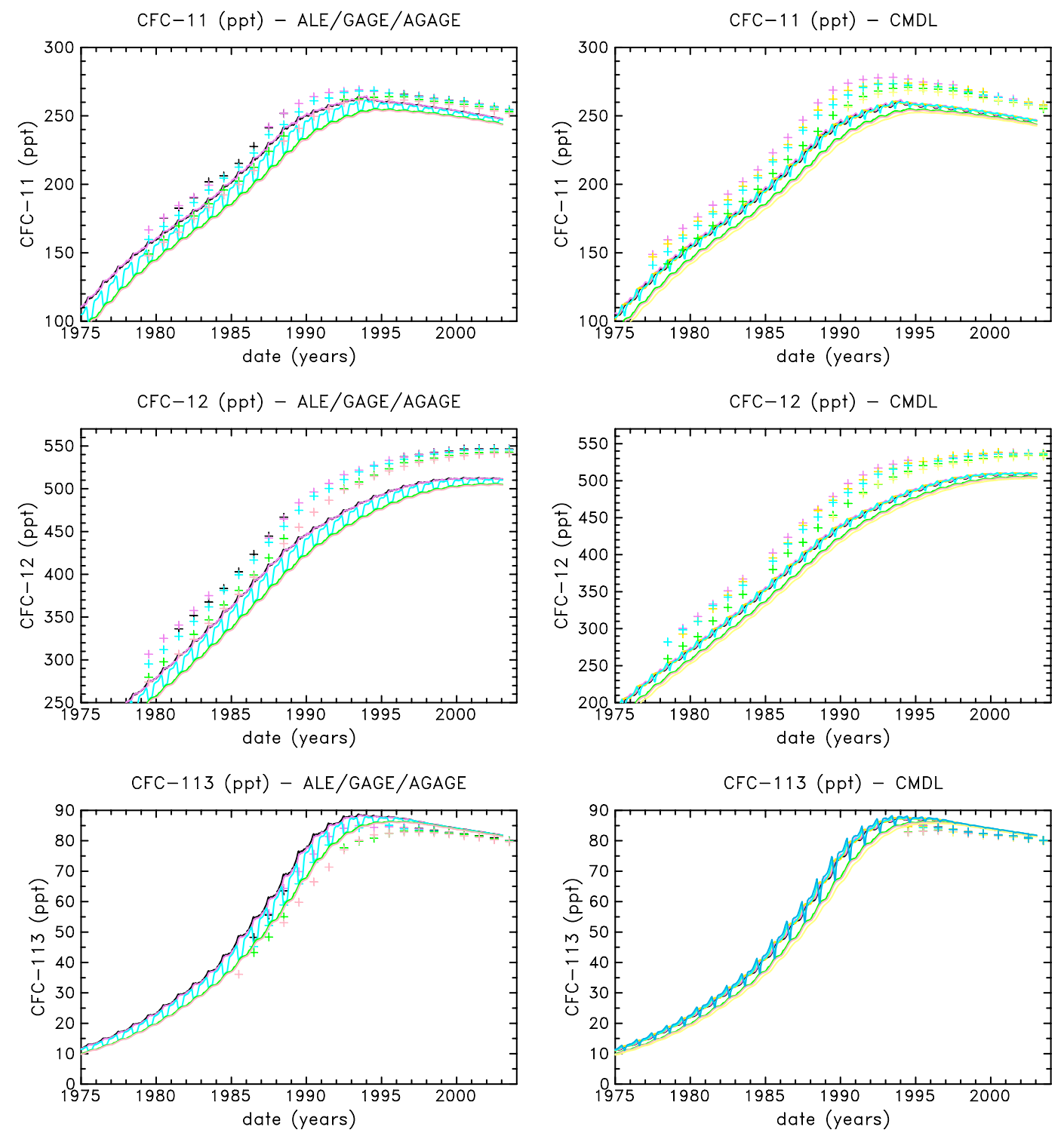

Fig. 2. Comparison of the chemistry model results (lines) for major CFCs with annual mean atmospheric data (plus signs). The different colours depict trends at ground level for different latitudes. Left panel: comparison with AGAGE data: violet: Adrigole (52 $\left.{ }^{\circ} \mathrm{N}\right)$ and Mace Head $\left(53^{\circ} \mathrm{N}\right)$, Ireland, black: Oregon $\left(45^{\circ} \mathrm{N}\right)$ and Trinidad Head $\left(41^{\circ} \mathrm{N}\right)$, USA, turquoise: Barbados $\left(13^{\circ} \mathrm{N}\right)$, green: Samoa $\left(14.3^{\circ} \mathrm{S}\right)$, pink: Cape Grim $\left(40.7^{\circ} \mathrm{S}\right)$, Australia. Right panel: comparison with ESRL data: black: Alert $\left(82.5^{\circ} \mathrm{N}\right)$, Canada, violet: Pt. Barrow $\left(71.3^{\circ} \mathrm{N}\right)$, Alaska, USA, orange: Niwot Ridge $\left(40.1^{\circ} \mathrm{N}\right)$, USA, turquoise: Mauna Loa $\left(19.5^{\circ} \mathrm{N}\right)$, Hawaii, blue: Cape Kumukahi, $\left(19.5^{\circ} \mathrm{N}\right), \mathrm{Hawaii}$ green: Samoa $\left(14.3^{\circ} \mathrm{S}\right)$, pink: Cape Grim $\left(40.7^{\circ} \mathrm{S}\right)$, Australia, yellow: South Pole $\left(90^{\circ} \mathrm{S}\right)$, Antarctica. The sites represented in turquoise (Barbados and Hawaii) show a high seasonal variability because the inter-tropical convergence zone shifts seasonally North and South of these measurement stations. A similar variability is observed in the monthly mean (instead of annual mean) observations.

effect of refrozen melt layers at Devon Island or other heterogeneities in firn (Martinerie et al., 1992). Fabre et al. (2000) have shown that the inverse modelling approach provides a better representation of diffusivity variations from one site to another than direct measurements on firn samples. Indeed, firn diffusivity appears to be sensitive to heterogeneities occurring at larger scale than the samples used for direct measurements.
Once the diffusivity profile at a given site is established for a reference gas, it can be used for another gas by simply scaling it by the ratio of molecular diffusion coefficients of the two gases. Therefore, a bias shared by all gases at one site may result from a bias in the diffusivity profile at this site. As in most previous studies, molecular diffusion coefficients for halocarbons are estimated from molecular volume calculations (Gilliland, 1934, described in Perry and Chilton, 1973). 

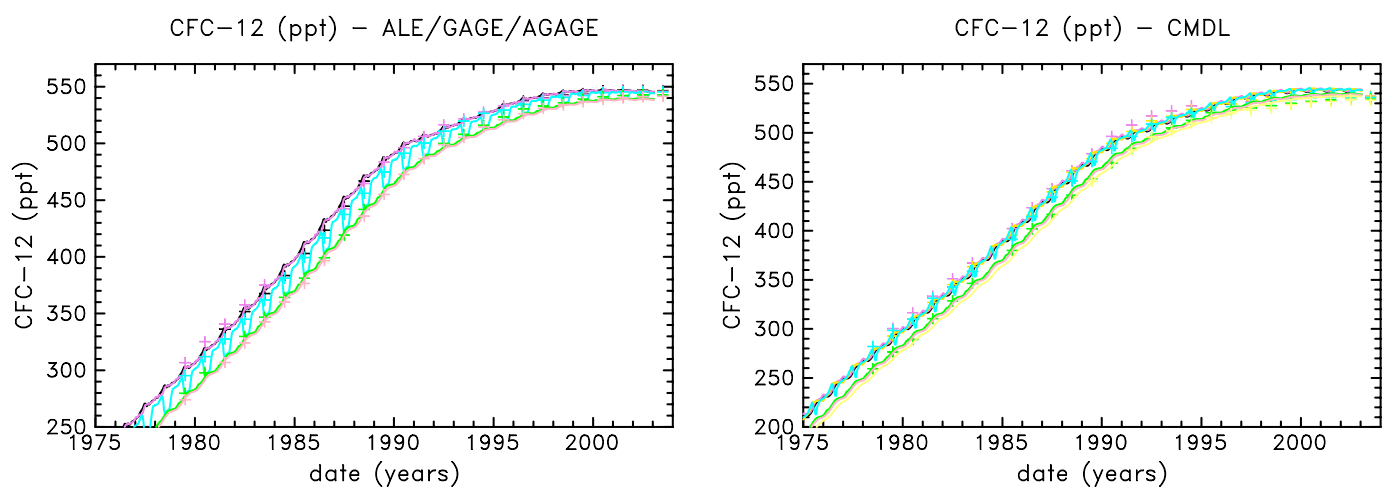

Fig. 3. Comparison of the chemistry model results (lines) for CFC-12 using adjusted emissions with annual mean atmospheric data (plus signs). The colours are defined in Fig. 2.

They are provided and evaluated against measurements in the supplementary material (http://www.atmos-chem-phys. net/9/3911/2009/acp-9-3911-2009-supplement.pdf).

\section{Validation of the atmospheric chemistry model}

The quality of the atmospheric chemistry model results is evaluated by comparison with surface, total column, and balloon-based measurements.

\subsection{Validation of surface concentrations}

Our surface concentration trends are compared with atmospheric measurements from multiple long-term observation sites from the ALE/GAGE/AGAGE (noted AGAGE in the following) and NOAA-CMDL/ESRL (further noted ESRL) monitoring networks (Montzka et al., 1999; Prinn et al., 2000). The major sources of uncertainties in the atmospheric cycle of long lived halocarbons are related to their emissions, their lifetimes (or loss rates) and their measurement calibration. These uncertainties are relatively small for CFC-11, CFC-12 and CFC-113 (WMO, 2007), thus these gases are used to discuss the validation of our chemistry model. A similar comparison for our other target gases is presented in the supplementary material (http://www.atmos-chem-phys.net/ 9/3911/2009/acp-9-3911-2009-supplement.pdf). According to WMO (2007), inter-calibration differences between ESRL and AGAGE are lower than $2 \%$ for CFC-11, CFC-12 and CFC-113. Our results (Fig. 2) under-predict the observations by $3-6 \%$ for CFC-11 and $6.5-9.5 \%$ for CFC-12, whereas they over-predict the measurements for CFC-113 by $2-7 \%$. These differences vary with time but stay within the uncertainty limits of emission estimates: between 5 and $9 \%$ (McCulloch et al., 2003) or 7.5-18\% (WMO, 2007).

Meridional distributions are well reproduced by our model results (Fig. 2). For these long lifetime gases, meridional gradients reflect their transport time from their production (mostly in the Northern hemisphere) to their measurement sites. The drastic reduction of their production rate following the Montreal and Kyoto protocols explains the strong decrease in their North to South concentration gradient over recent years. For CFC-11, the difference between model and data is higher with the ESRL record than with the AGAGE record (Fig. 2). As the model results are basically the same on both plots, this difference is due to inter-calibration differences between the two datasets.

Additional chemistry model simulations were performed with halocarbon emissions adjusted to fit the atmospheric measurements. The results for CFC-12 are shown in Fig. 3. Here emissions were increased by $10 \%$ before 1991 and decreased by $10 \%$ between 1991 and 1995, no adjustment was performed afterwards. Such chemistry model results with halocarbon emissions adjusted to fit atmospheric measurements will be used to constrain the firn diffusion model in order to check the consistency between firn air and atmospheric measurements.

\subsection{Comparison with balloon and column measure- ments for CFC-12}

The validation of our chemistry model has been completed for CFC-12 by comparison with stratospheric balloon measurements and vertical column measurements. This aims at further testing the model transport and CFC-12 destruction in the stratosphere. A significant bias in model vertical transport would likely affect the destruction rate and global sink of our target gases, which are destroyed only in the middle atmosphere.

Engel et al. (1998) collected balloon data since 1978 at Aire sur l'Adour, Gap ( $44^{\circ} \mathrm{N}$, France) and Kiruna $\left(68^{\circ} \mathrm{N}\right.$, Sweden) in order to derive historical trends of CFC-12 in the stratosphere. The CFC-12 mixing ratio trends were compiled for three $\mathrm{N}_{2} \mathrm{O}$ levels, considered as a surrogate for altitude (lowermost stratosphere, around $19 \mathrm{~km}$ and around $21.5 \mathrm{~km}$ ). In the model, the $\mathrm{N}_{2} \mathrm{O}$ surface concentration 

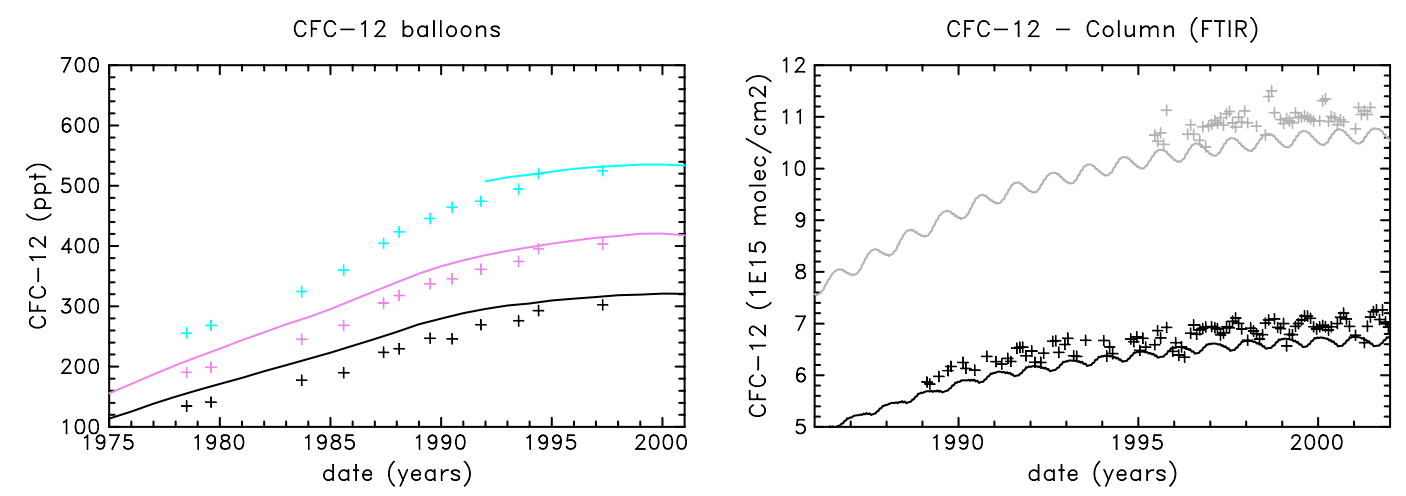

Fig. 4. Comparison of modelled CFC-12 concentrations (lines) with stratospheric balloon (left panel) and vertical column (right panel) measurements (plus signs). Left panel: CFC-12 mixing ratios at $\mathrm{N}_{2} \mathrm{O}$ levels of $310 \mathrm{ppb}$ (turquoise), $250 \mathrm{ppb}$ (violet) and $200 \mathrm{ppb}$ (black). Right panel: Vertical column abundances of CFC-12 above the Jungfraujoch $\left(46^{\circ} \mathrm{N}, 3580 \mathrm{~m}\right.$, in black) and Wollongong ( $34^{\circ} \mathrm{S}, 30 \mathrm{~m}$, in grey) measurement stations. The model results shown here use adjusted emissions (as in Fig. 3).

scenario was built using AGAGE atmospheric measurements at Cape Grim, Australia from 1978 to 2002 (Prinn et al., 1990, 2000) and Antarctic firn and ice core data before 1978. Two smoothed scenarios were built using the records of Machida et al. (1995) and MacFarling Meure et al. (2006). They are consistent within $0.5 \mathrm{ppb}$. A graphic comparison with Fig. 3 in Battle et al. (1996) indicates that the atmospheric trend inferred from the South Pole firn record is about 2-3 ppb lower than the two above scenarios, although South Pole data are within the range of the variability in the Machida et al. (1995) record. The $\mathrm{N}_{2} \mathrm{O}$ meridional gradient is positive from South to North and is stronger close to the Equator (IPCC, 2001). Modelled $\mathrm{N}_{2} \mathrm{O}$ mixing ratios are consistent with AGAGE measurements at all latitudes. Model results for CFC-12 at the three $\mathrm{N}_{2} \mathrm{O}$ levels are virtually identical for the two launch site latitudes $\left(44^{\circ} \mathrm{N}\right.$ and $\left.68^{\circ} \mathrm{N}\right)$. They are compared with observation on the left panel of Fig. 4.

Model results in Fig. 4 were computed with CFC-12 emissions adjusted to obtain surface mixing ratios consistent with surface station measurements (see Sect. 3.1), they slightly overestimate the measurements, but the results obtained with raw CFC-12 emissions fit them almost perfectly. Considering the 5\% precision of balloon measurements (Engel et al., 1998), our model results are globally consistent with observations. The results obtained with the two $\mathrm{N}_{2} \mathrm{O}$ ice core scenarios show differences in CFC-12 concentrations lower than 1ppt. Model results at the $310 \mathrm{ppb} \mathrm{N}_{2} \mathrm{O}$ level are plotted only after 1992 because modelled $\mathrm{N}_{2} \mathrm{O}$ concentrations did not reach $310 \mathrm{ppb}$ before that time. This is consistent with yearly average AGAGE surface data, which reach this level in 1991. Thus we suggest that early measurements of CFC12 at $310 \mathrm{ppb} \mathrm{N}_{2} \mathrm{O}$ were made on tropospheric polluted air intruded into the lower stratosphere.

Our model results were further compared with total column densities of CFC-12 from ground-based FTIR spec- trometers at Jungfraujoch in Switzerland and Wollongong in Australia (Zander et al., 2000; NCEP, 2006). Since the elevation at the Jungfraujoch station is much higher than Wollongong, column densities are higher at Wollongong than at Jungfraujoch (right panel in Fig. 4). This hides slight differences due to meridional variations of CFC-12 mixing ratio, described in Sect. 3.1. Model results underestimate the experimental data by approximately $6 \%$. However, considering the uncertainties reported for the Jungfraujoch $( \pm 4 \%)$ and Wollongong (15\%) measurements, as well as the uncertainties on emissions used to constrain the model, the modelled column densities are still consistent with measurements.

Our model results somewhat overestimate the balloon measurements, but underestimate total column data, thus no clear bias of the vertical structure of our modelled CFC-12 concentrations can be detected.

\section{Trace gas measurements in firn air}

Numerous trace gas measurements were performed at five Arctic and Antarctic drilling sites within the FIRETRACC and CRYOSTAT EC projects (FIRETRACC, 2007; CRYOSTAT, 2007). The major characteristics of these sites are presented in Table 1. The experimental setup used to extract firn air from boreholes in ice sheets is similar to the original technique described in Schwander et al. (1993). The modifications (Sturges et al., 2001) include on-site continuous measurements of $\mathrm{CO}_{2}$ (LI-COR analysis) allowing the absence of contamination with contemporary air to be monitored. Only a few surface air samples were taken during the short (about a month) firn drilling periods. Our surface values are thus less reliable than monthly mean data from atmospheric measurement networks which involve numerous samples. We should note that samples from the two last depth levels at Berkner Island are thought to be contaminated 
Table 1. Characteristics of the firn drilling sites. Temp. stands for mean annual temperature, and Accu. for snow accumulation rate in water equivalent units. Drill site abbreviations: DI: Devon Island, NGR: North GRIP, BKN: Berkner Island, DML: Dronning Maud Land, DC: Dome C.

\begin{tabular}{llllll}
\hline Site & $\begin{array}{l}\text { Drill } \\
\text { date }\end{array}$ & $\begin{array}{l}\text { Lat./Lon. } \\
(\text { degrees })\end{array}$ & $\begin{array}{l}\text { Alt. } \\
(\mathrm{m}) .\end{array}$ & $\begin{array}{l}\text { Temp. } \\
\left({ }^{\circ} \mathrm{C}\right)\end{array}$ & $\begin{array}{l}\text { Accu. } \\
(\mathrm{cm} / \mathrm{yr})\end{array}$ \\
\hline DI & $04 / 1998$ & $75 \mathrm{~N} / 82 \mathrm{~W}$ & 1800 & -23 & 30 \\
NGR & $07 / 2001$ & $75 \mathrm{~N} / 42 \mathrm{~W}$ & 2975 & -32 & 17 \\
BKN & $01 / 2003$ & $79 \mathrm{~S} / 45 \mathrm{~W}$ & 900 & -26 & 13 \\
DML & $01 / 1998$ & $77 \mathrm{~S} / 10 \mathrm{~W}$ & 2300 & -38 & 7 \\
DC & $01 / 1999$ & $75 \mathrm{~S} / 124 \mathrm{E}$ & 3240 & -53 & 3.5 \\
\hline
\end{tabular}

by a leak in the air pumping system (Worton et al., 2007) and should be considered with caution. Halocarbon and $\mathrm{SF}_{6}$ measurements presented in this paper were performed at both the University of East Anglia (UEA) and National Center for Atmospheric Research (NCAR) using gas chromatography combined with mass spectroscopy (GC-MS). These analytical techniques are described in Sturges et al. (2001) and references therein. Detection limits are about $0.002 \mathrm{ppt}$ for UEA measurements and $0.02-0.03 \mathrm{ppt}$ for NCAR measurements. Among the measured concentrations reported here, only CFC- 115 results at the deepest levels of Northern Hemisphere sites fall below NCAR detection limits. Additional measurements of $\mathrm{SF}_{6}$ were done at the Max Planck Institute of Mainz on large volume samples (Sturges et al., 2000). Most of the data presented in this paper are publicly available in the FIRETRACC and CRYOSTAT databases (FIRETRACC, 2007; CRYOSTAT, 2007).

The firn air data dispersion (or spreading) was evaluated using multiple measurement at the same depth level, by calculating the standard deviation resulting from these concentration differences. Although data from all drilling sites were taken into account, the overall values in Table 2 are based on only about 20 replicates. However, we should note that higher values of concentration differences frequently occur in the upper part of the firn (top 15-20 m), where firn air concentration are potentially influenced by short term atmospheric variations. The inter-calibration differences between UEA and NCAR measurements were carefully examined on samples measured at the same site and depth. The resulting values (column 4 in Table 2) were used to convert NCAR data to values consistent in scale with UEA measurements.

\section{Validation of the firn diffusion model}

The major uncertainties on simulated vertical profiles in the firn arise from the atmospheric trends used as input, which rely on somewhat uncertain emission trends (Sect. 3.1), uncertainties on firn air measurements (Sect. 4) and on the firn model, which is mainly constrained by the firn diffu-
Table 2. Quality parameters for trace gas measurements in firn. STD stands for standard deviation (ppt), Calibr. stands for intercalibration differences, and WMO refers to WMO (2007). When two numbers are given in the STD UEA column, the first one refers to measurements made with the PLOT chromatographic column, whereas the second one refers to the DB5 column (Sturges et al., 2000, 2001).

\begin{tabular}{lllll}
\hline Gas & $\begin{array}{l}\text { STD } \\
\text { UEA }\end{array}$ & $\begin{array}{l}\text { STD } \\
\text { NCAR }\end{array}$ & $\begin{array}{l}\text { Calibr. } \\
\text { UEA-NCAR }\end{array}$ & $\begin{array}{l}\text { Calibr. } \\
\text { WMO }\end{array}$ \\
\hline CFC-11 & 3 & 1 & $+1 \%$ & $<2 \%$ \\
CFC-12 & $7 / 13$ & 3 & $+1.5 \%$ & $<2 \%$ \\
CFC-113 & $1 / 1$ & 3 & $+1 \%$ & $<2 \%$ \\
CFC-114 & 0.3 & 0.2 & $+20 \%$ & \\
CFC-115 & 0.2 & 0.3 & $+20 \%$ & \\
$\mathrm{CCl}_{4}$ & 4 & 6 & $+6 \%$ & $3-4 \%$ \\
$\mathrm{SF}_{6}$ & 0.1 & & & \\
\hline
\end{tabular}

sivity profiles (Sect. 2.2). CFC-11, CFC-12 and CFC-113 have long atmospheric trend records and low uncertainties on their budget, thus they are again used here for firn model evaluation. The adjusted atmospheric trends calculated with the chemistry model (Sect. 3.1) were used as input to the firn diffusion model and are compared with measured concentrations in firn (Fig. 5). The overall agreement between model results and observations is very good. Previous estimates of firn diffusivities (FIRETRACC, 2007; CRYOSTAT, 2007) produced systematic differences between model results and observations for all gases at the bottom of the Devon Island firn and at intermediate depths of the Dronning Maud Land firn. Such differences were attributed to a bias induced by the firn diffusivity profiles (see Sect. 2.2). New calculations of the firn diffusivities were performed for all firn drilling sites with less detailed adjustments to the reference gas. The resulting smoother diffusivity profiles (see supplement http://www.atmos-chem-phys.net/9/3911/2009/ acp-9-3911-2009-supplement.pdf) produce a better agreement with halocarbon measurements. At Devon Island, a model/data discrepancy remains between 25 and $30 \mathrm{~m}$ depth: the data show a drop in the concentrations of major CFCs (Fig. 5), whereas the model produces a smooth decrease. 197 refrozen melt layers with thicknesses ranging between 0.5 and $6.5 \mathrm{~cm}$ were logged in the Devon Island firn core, and the thickest melt layer was found at $28 \mathrm{~m}$ depth. Although the $25-30 \mathrm{~m}$ depth range is not the only interval where thick melt layers are observed, the 13-30 m region shows the highest accumulation of melt layers (in terms of total number as well as cumulated thickness). The effect of impermeable layers depends on their horizontal extent and continuity. In our model, the firn is considered as a homogeneous medium and singular layers cannot be reproduced. The drop in observed concentrations around $25-30 \mathrm{~m}$ depth is thus likely due to the presence of melt layers at Devon Island. Model/data discrepancies showing parallel signals (similar slopes) may be 

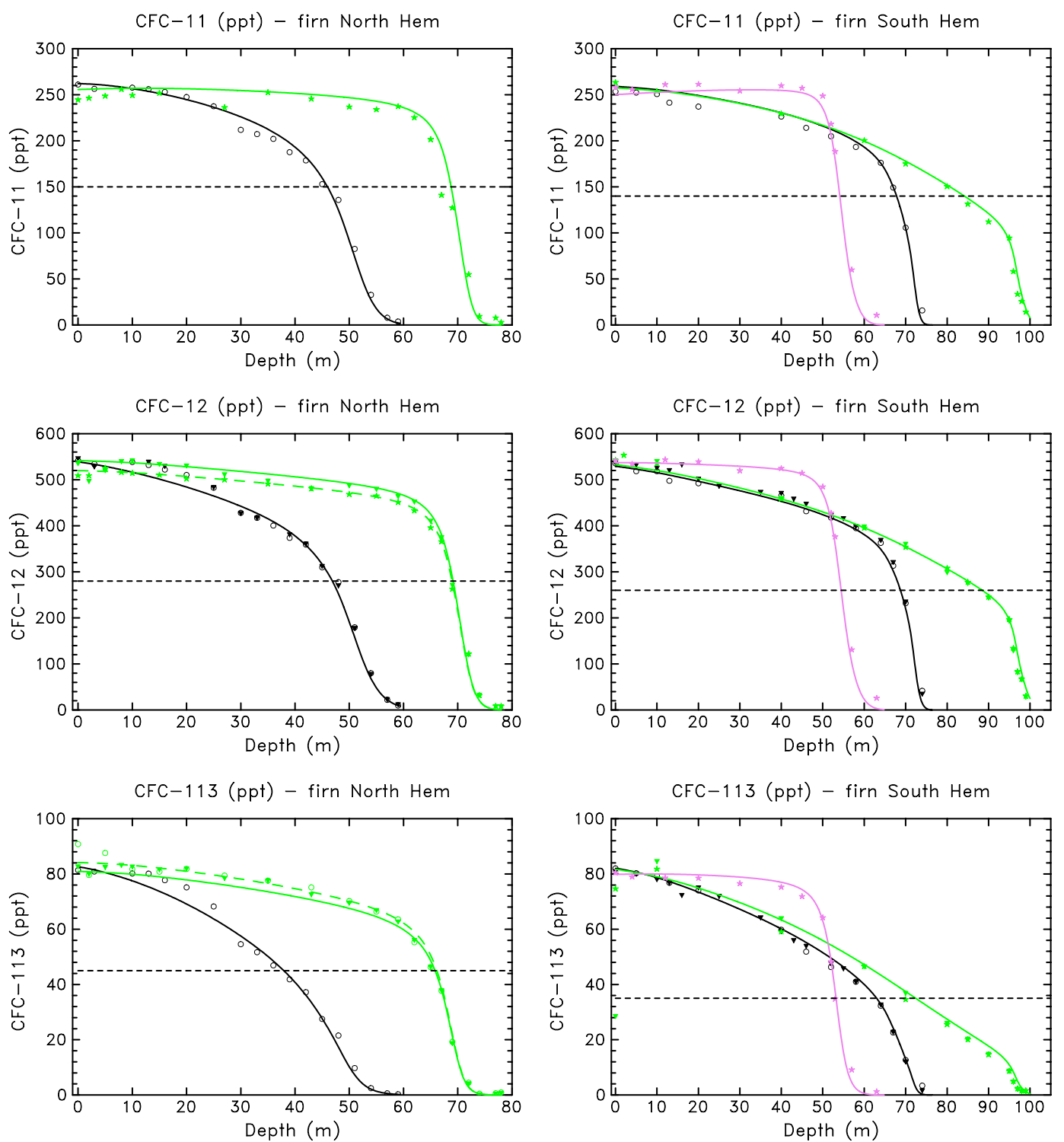

Fig. 5. Comparison of the firn model results (continuous lines) for major CFCs with FIRETRACC and CRYOSTAT data (symbols). Left panel: comparison with North Hemisphere drill sites: Devon Island in black, North GRIP in green. Right panel: comparison with South hemisphere drill sites: Berkner Island in violet, Dronning Maud land in black, Dome C in green. Stars and triangles show UEA measurements performed respectively with a PLOT and DB5 chromatographic columns, open circles depict NCAR measurements. Horizontal black dashed lines illustrate the lowest atmospheric concentrations measured in the relevant hemisphere by the AGAGE or ESRL networks. The green dashed lines show the impact of reducing atmospheric CFC-12 concentrations by $4 \%$ and increasing atmospheric CFC- 113 concentrations by $4 \%$.

due to calibration issues on the firn measurements. A calibration bias would likely affect all measurements by the same percent change. The dashed green lines for CFC-12 and CFC-113 at North GRIP illustrate this effect: the atmospheric concentration scenario was reduced by $4 \%$ for CFC12 and increased by $4 \%$ for CFC- 113 . These scenario adjustments produce model results in agreement with the firn data. Such concentration adjustments have a negligible impact on the lower part of the firn record (Fig. 5).
Overall, the modelled and observed slopes are in excellent agreement in the upper part of the firn. The gentle slopes at small depths indicate that the upper firn is a fast diffusive medium. Steeper slopes are obtained at the three sites drilled in 1998-1999 (Table 1) than at North GRIP and Berkner, drilled in 2001-2003. This might be due to the recent reduced increase or decrease in major CFC trends. However, a sensitivity test performed by running the diffusion model only until January 1998 at North GRIP and Berkner showed 
Table 3. Comparison of ages in the firn with atmospheric scenario ages at the deepest measurement level(s). Scen age is the age in the atmospheric scenario corresponding to the concentration measured in the firn. Firn age presents the trace gas mean ages (sum over time of ages multiplied by their probability) in the firn, and between brackets: ages at $15 \%, 50 \%$ (median age) and $85 \%$ accumulated probability. Drilling sites abbreviations are DI: Devon Island, NGR: North GRIP, BKN: Berkner, DML: Dronning Maud Land, DC: Dome C.

\begin{tabular}{|c|c|c|c|c|c|c|c|c|}
\hline $\begin{array}{l}\text { Site } \\
\text { Depth }\end{array}$ & $\begin{array}{c}\text { DI } \\
59 \mathrm{~m}\end{array}$ & $\begin{array}{l}\text { NGR } \\
74 \mathrm{~m}\end{array}$ & $\begin{array}{l}\text { NGR } \\
78 \mathrm{~m}\end{array}$ & $\begin{array}{l}\mathrm{BKN} \\
57 \mathrm{~m}\end{array}$ & $\begin{array}{l}\text { BKN } \\
63 \mathrm{~m}\end{array}$ & $\begin{array}{l}\text { DML } \\
74 \mathrm{~m}\end{array}$ & $\begin{array}{c}\text { DC } \\
98 \mathrm{~m}\end{array}$ & $\begin{array}{c}\text { DC } \\
99 \mathrm{~m}\end{array}$ \\
\hline \multicolumn{9}{|l|}{$\mathrm{CH}_{4}$} \\
\hline Scen age & 45 & 39 & 56 & 28 & 52 & 32 & 21 & \\
\hline Firn age & $41(31 / 39 / 50)$ & $38(29 / 36 / 47)$ & $60(50 / 58 / 69)$ & $32(13 / 25 / 53)$ & $62(35 / 56 / 90)$ & $37(22 / 34 / 52)$ & $21(10 / 18 / 32)$ & \\
\hline \multicolumn{9}{|l|}{$\mathrm{CO}_{2}$} \\
\hline Scen age & 34 & 37 & 43 & 28 & 45 & 34 & 23 & \\
\hline Firn age & $46(35 / 44 / 57)$ & $43(33 / 41 / 54)$ & $65(54 / 63 / 76)$ & $38(17 / 31 / 61)$ & $72(43 / 66 / 101)$ & $44(28 / 41 / 61)$ & $29(15 / 25 / 44)$ & \\
\hline \multicolumn{9}{|l|}{$\mathrm{SF}_{6}$} \\
\hline Scen age & 36 & 38 & 38 & 29 & 37 & 33 & & 29 \\
\hline Firn age & $55(41 / 52 / 69)$ & $52(39 / 50 / 65)$ & $74(60 / 71 / 87)$ & $48(24 / 41 / 72)$ & $85(55 / 79 / 115)$ & $57(37 / 53 / 76)$ & & $51(28 / 46 / 75)$ \\
\hline \multicolumn{9}{|l|}{ CFC- 12} \\
\hline Scen age & 45 & 41 & 50 & 32 & 43 & 35 & 33 & 38 \\
\hline Firn age & $55(41 / 52 / 69)$ & $52(39 / 50 / 65)$ & $74(60 / 72 / 87)$ & $48(24 / 41 / 72)$ & $85(56 / 80 / 115)$ & $57(37 / 53 / 76)$ & $45(23 / 40 / 67)$ & $51(28 / 46 / 75)$ \\
\hline \multicolumn{9}{|l|}{ CFC-11 } \\
\hline Scen age & 43 & 41 & 46 & 32 & 41 & 34 & 33 & 36 \\
\hline Firn age & $56(42 / 53 / 71)$ & $54(40 / 51 / 67)$ & $75(62 / 73 / 89)$ & $49(25 / 43 / 74)$ & $87(58 / 82 / 117)$ & $59(39 / 55 / 79)$ & $48(25 / 42 / 72)$ & $55(30 / 49 / 80)$ \\
\hline \multicolumn{9}{|l|}{ CFC-113 } \\
\hline Scen age & 46 & 46 & 43 & 28 & 41 & 32 & 36 & 36 \\
\hline Firn age & $60(44 / 56 / 76)$ & $57(42 / 54 / 72)$ & $79(64 / 76 / 94)$ & $53(28 / 46 / 78)$ & $92(62 / 86 / 122)$ & $64(43 / 60 / 85)$ & $55(29 / 49 / 82)$ & $62(35 / 56 / 90)$ \\
\hline
\end{tabular}

that the slopes in the upper part of the firn remained lower at these two sites. Thus this behaviour may also be a characteristic of medium accumulation rate sites where no melting occurs. Continuous atmospheric measurements of CFC-11 and CFC-12 started in 1979, and in 1985 for CFC-113. The comparison of concentrations measured at that time with firn air records suggests that only the deepest part of the firn records contain significant information about the period pre-dating ambient air measurements for these gases. In this earlier part of the records, the model/data agreement remains correct although the high slopes and age mixing in the firn lead to increased uncertainties.

The uncertainties in the lower part of the firn records can be better characterized by calculating trace gas age distributions in the firn. Following the classical Green function approach, the age distributions in the firn can be established by studying its response to a pulse in trace gas concentration. Such an approach has already been used in previous studies (e.g. Schwander et al., 1993; Trudinger et al., 1997). It allows the calculation of the probability to have trace gas of a given age at a given firn depth. The ages in the firn depend on the particular trace gas through its diffusion coefficient. Our target gases are slow diffusing species with relative diffusion coefficients with respect to $\mathrm{CO}_{2}$ ranging between 0.495 (for CFC-113) and 0.62 (for $\mathrm{SF}_{6}$ ), whereas methane is a small and thus fast diffusing molecule. Table 3 presents the firn model derived mean ages, as well as the ages at $15 \%, 50 \%$ and $85 \%$ accumulated probability. Age distributions in the firn are asymmetric (see Sect. 6.1), this is why the mean age is located between the $50 \%$ and $85 \%$ accumulated probability ages. By contrast, the maximum probability age (mode age) is located between the $15 \%$ and $50 \%$ (median) accumulated probability ages. In Table 3, the trace gases are presented in decreasing order of their diffusion coefficients. Thus the model-derived "firn ages" at a given depth are increasing when going down the table. The modelled firn ages are compared with the atmospheric "scenario ages" corresponding to the mean concentrations measured at the lowest sampled levels in the firn. We should note that mean age and scenario age (or effective age) are not theoretically identical for trace gases undergoing a nonlinear time-trend in the atmosphere (Trudinger et al., 2002). As trace gas concentrations at the bottom of polar firns are low, they are subject to maximum experimental errors. Such errors can be visualized in Table 3 by the fact that scenario ages show inconsistencies between the different trace gases by not following the theoretical anti-correlation between diffusion coefficient and trace gas age. In this frame, firn ages and scenario ages are reasonably consistent except at the bottom of North GRIP (78 m) and Berkner (63 m) firns. At these sites, the agreement is satisfying at $74 \mathrm{~m}$ and $57 \mathrm{~m}$ depth respectively. At Berkner Island, the measurements below $60 \mathrm{~m}$ depth are suspected of contamination. Thus both the scenario ages and the firn ages (based on $\mathrm{CH}_{4}$-derived diffusivity) are unreliable. At North GRIP, the scenario age difference between $74 \mathrm{~m}$ and $78 \mathrm{~m}$ varies strongly from one trace gas to another. The $\mathrm{SF}_{6}$ scenario age is invariant and the CFC-113 age decreases between $74 \mathrm{~m}$ and $78 \mathrm{~m}$. It reflects unchanged $\left(\mathrm{SF}_{6}\right)$ or slightly increasing (CFC-113, see Fig. 5) concentrations. We thus suggest that measurements at the lowest 

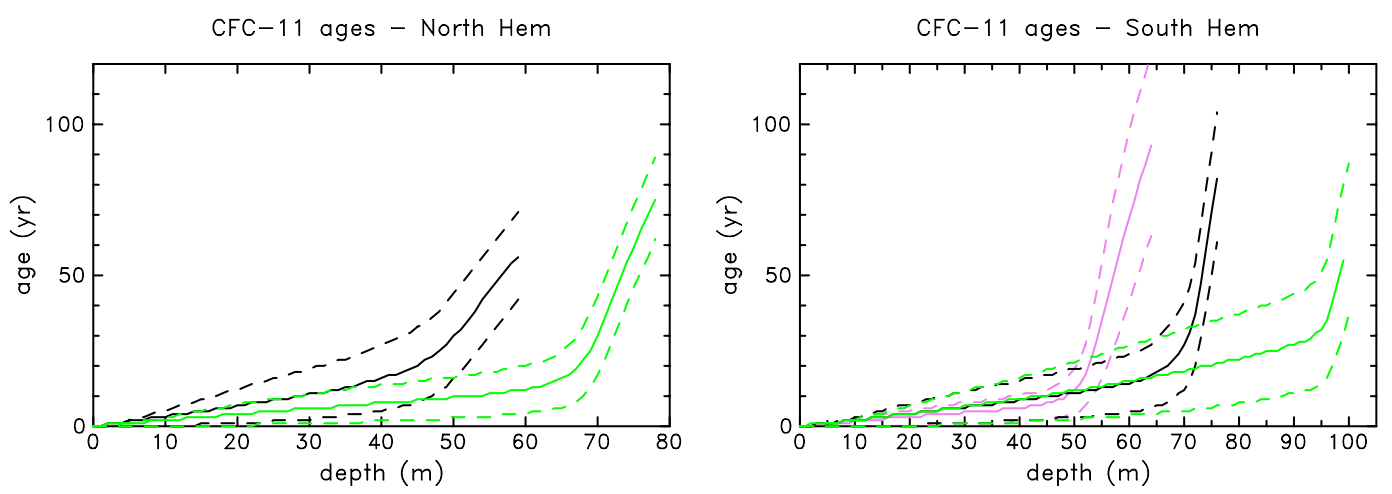

Fig. 6. CFC-11 age versus depth. Continuous lines: mean age, lower dashed lines: age at $15 \%$ accumulated probability, higher dashed lines: age at $85 \%$ accumulated probability. Colours: same as Fig. 5.
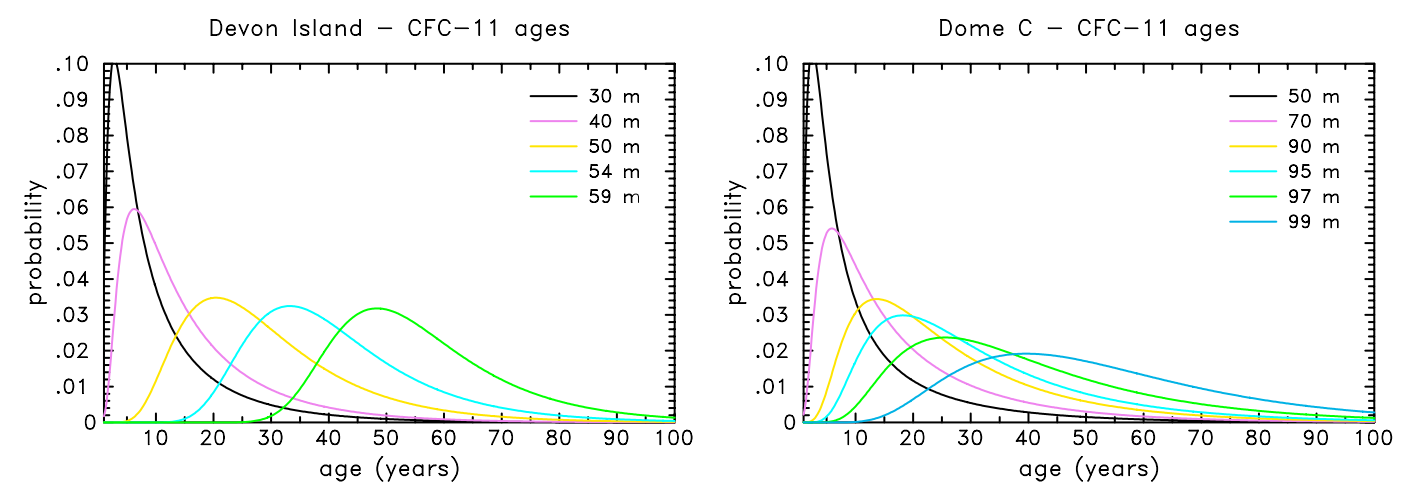

Fig. 7. CFC-11 age distributions at selected depths in the Devon Island and Dome C firns.

level of the North GRIP firn might be slightly contaminated. At this depth, the air flow rate through the sampling apparatus was reduced by two thirds, indicating a nearly impermeable firn. This may have caused ambient air leaks into the sampling system. Similar unchanged or increased concentration anomalies at deepest firn levels were obtained by Butler et al. (1999), who sampled three Antarctic and Greenland sites with $1 \mathrm{~m}$ to $1.5 \mathrm{~m}$ depth resolution (detailed results can be found in the ESRL database Elkins et al., 1998). The deep Dome $\mathrm{C}$ firn shows surprisingly young ages. Scenario ages and firn ages look generally consistent at this site (Table 3), however we should note that the firn model systematically overestimates measured concentrations in the lower part of the Dome $\mathrm{C}$ firn (Fig. 5). This may induce an underestimation of the firn ages.

\section{Results and discussion}

\subsection{Age distributions in the firn}

As our target species have similar diffusion coefficients, their age distributions show relatively small variations from one gas to another (Table 3). Figure 6 illustrates the depth profile of CFC-11 ages which has an intermediate relative diffusion coefficient of $D_{\mathrm{CFC}-11} / D_{\mathrm{CO}_{2}}=0.575$. All drill sites show a distinct behaviour in the upper firn (slow increase in age with depth) and the lower firn (fast increase in age). The slope change in age-depth profile is less marked at Devon Island than other sites. We attribute this feature to the presence of refrozen melt layers, which decrease the diffusivity in the upper part of the firn. Devon Island is thus our best site if we consider the regularity of the depth-age profile (i.e. the least contrasted gentle/steep slope areas). However the age distribution at Devon Island is wider than at North GRIP (Table 3). This might be related to the low diffusivity of the Devon Island firn, which could lead to increased age mixing at equivalent depths.

Mean ages plotted in Fig. 6 reach their maximum at the last depth before full close-off. If we consider the last measurement depth and exclude the lowest levels at North GRIP and Berkner Island, where firn ages are inconsistent with atmospheric scenario ages (Table 3), maximum CFC-11 mean ages vary between 49 and 59 years before time of drilling.

In the upper firn, the age distribution width is smaller at North GRIP and Berkner Island than at other sites. Upper firn 
age distributions are highly asymmetric (Fig. 7). This asymmetry decreases with depth. The lower firn age distributions show a general tendency of widening for sites with lower snow accumulation rates, as illustrated in Fig. 7. However, the detailed site to site variations are somewhat complex and discussed in the supplement (http://www.atmos-chem-phys. net/9/3911/2009/acp-9-3911-2009-supplement.pdf).

Overall, the two Arctic sites show no significant influence of air less than 30 years old at the deepest reliable measurement level, whereas Antarctic sites show an influence of 15 to 25 years old air at all reliable measurement depths. On the other hand, at the deepest levels of Antarctic sites, 100 years old air still has an influence on trace gas concentrations in firn. Therefore, site to site differences in age distributions imply that a multi site approach provides more constraints on past trace gas trends.

\subsection{Historical concentration trends}

\subsubsection{Major CFCs (CFC-11, CFC-12)}

Sturrock et al. (2002) used firn model inversion techniques to derive atmospheric trends from measurements in Law Dome (Antarctica) firn for long lived halocarbons. For the recent past, the Sturrock et al. (2002) trends are partially constrained with atmospheric and Cape Grim air archive data (Trudinger et al., 2002). Figure 8 compares these concentration based scenarios to our chemistry model and emissions based trends. An almost perfect agreement is obtained for CFC-11 and CFC-12. These results are also qualitatively consistent with the trend histories calculated by Butler et al. (1999) using industrial emission models and atmospheric measurements. We should note that during the atmospheric record period, our approach is somewhat equivalent to Sturrock et al. (2002) because some adjustments were performed on emission scenarios in order to fit the atmospheric records (see Sect. 3.1). Uncorrected and corrected emissions are plotted in Fig. 9, the exact correction factors are given in the supplementary material (http://www.atmos-chem-phys.net/ 9/3911/2009/acp-9-3911-2009-supplement.pdf). The adjustment to atmospheric data in Sturrock et al. (2002) and our study represents a strong constraint for CFC-11 and CFC12 which have a long atmospheric record. The continuing agreement before 1978 indicates a good consistency between the firn records and emission histories for these gases. The firn drilling site of Sturrock et al. (2002) has an exceptionally high temperature and low close-off depth, which induce a very narrow age distribution (standard deviation of about five years (Sturrock et al., 2002)). On the other hand, only six depth levels were sampled for halocarbons in this shallow firn. Three of these levels show CFC-11 and CFC-12 concentrations lower than the 1978 atmospheric levels, two of them have near zero concentrations. Atmospheric emission histories used to constrain our chemistry model have a much higher time resolution (one year). Thus the consistency of our results with Sturrock et al. (2002) arises from both the consistency of early emissions with their firn record and the relative smoothness of the emission trends.

Measured concentrations at the bottom of the firn range between 4 and $10 \mathrm{ppt}$ for CFC-11, and 9 and $14 \mathrm{ppt}$ for CFC12 (Fig. 5) at the narrow age distribution Arctic sites. Higher values of 11-18 and 27-44 ppt for CFC-12 are observed at the Antarctic sites. This is likely to be due to the higher impact of recent air on bottom level concentrations at our Antarctic sites (Sect. 6.1). Our lowest concentration levels are consistent with those obtained by Butler et al. (1999). Lower values (0.4-0.7 ppt for CFC-11 and 1.6-2.1 ppt for CFC-12) were observed at the very narrow age distribution Law Dome site sampled by Sturrock et al. (2002). The consistency between our emission based model results and firn measurements (Fig. 5) confirms the absence of significant CFC-11 and CFC-12 concentrations in the atmosphere before the start of their industrial emissions.

\subsubsection{Other CFCs (CFC-113, CFC-114 and CFC-115)}

Unlike major CFCs, our modelled CFC-113, CFC-114 and CFC-115 atmospheric trends show some differences with the Sturrock et al. (2002) scenarios (Fig. 8). The Sturrock et al. (2002) CFC-113 data suggest higher concentrations than ours in the 1970-1980 period (its AGAGE atmospheric record starts in 1985). To our knowledge, there are no CFC114 and CFC-115 atmospheric trend records before 2003. Thus our emission based scenario was only linearly modified to fit the Cape Grim air archive data. This correction is important (15\%) for CFC-114 (Fig. 9). Sturrock et al. (2002) applied a correction to put UEA (Oram, 1999) Cape Grim air archive data on the AGAGE calibration scale. This rescaling (AGAGE/UEA=0.94 for CFC-114 and 0.96 for CFC-115) probably explains the $1 \mathrm{ppt}$ difference in recent $\mathrm{CFC}-114$ concentrations (Fig. 8) and affects less CFC-115 (0.35 ppt). The Sturrock et al. (2002) trend scenario for CFC-114 starts in 1960 because the two lowest depths sampled at their Law Dome sites showed undetectable concentrations. On the other hand, CFC-114 emissions show a peculiar behaviour with an abrupt increase between 1944 and 1946, followed by a stabilization in 1950-1960 (Fig. 9). This results in a steeper and more constant slope at the beginning of our trend scenario than for other CFCs. Overall, our model results are consistent with Sturrock et al. (2002) for the recent past, but we obtain higher levels of CFC-114 before 1978 and lower levels of CFC-115 in 1975-1985 (Fig. 8). We should note that for CFC-113 and CFC-115, the Law Dome firn air record suggests higher concentrations than the early Cape Grim air archive (around 1980) (Sturrock et al., 2002).

In order to test if the above differences in time trends significantly affect our firn depth profiles, we ran our firn diffusion model with the Sturrock et al. (2002) atmospheric scenarios (Fig. 10). The relatively small difference in CFC113 trend scenarios mostly impact the DML and Dome C 

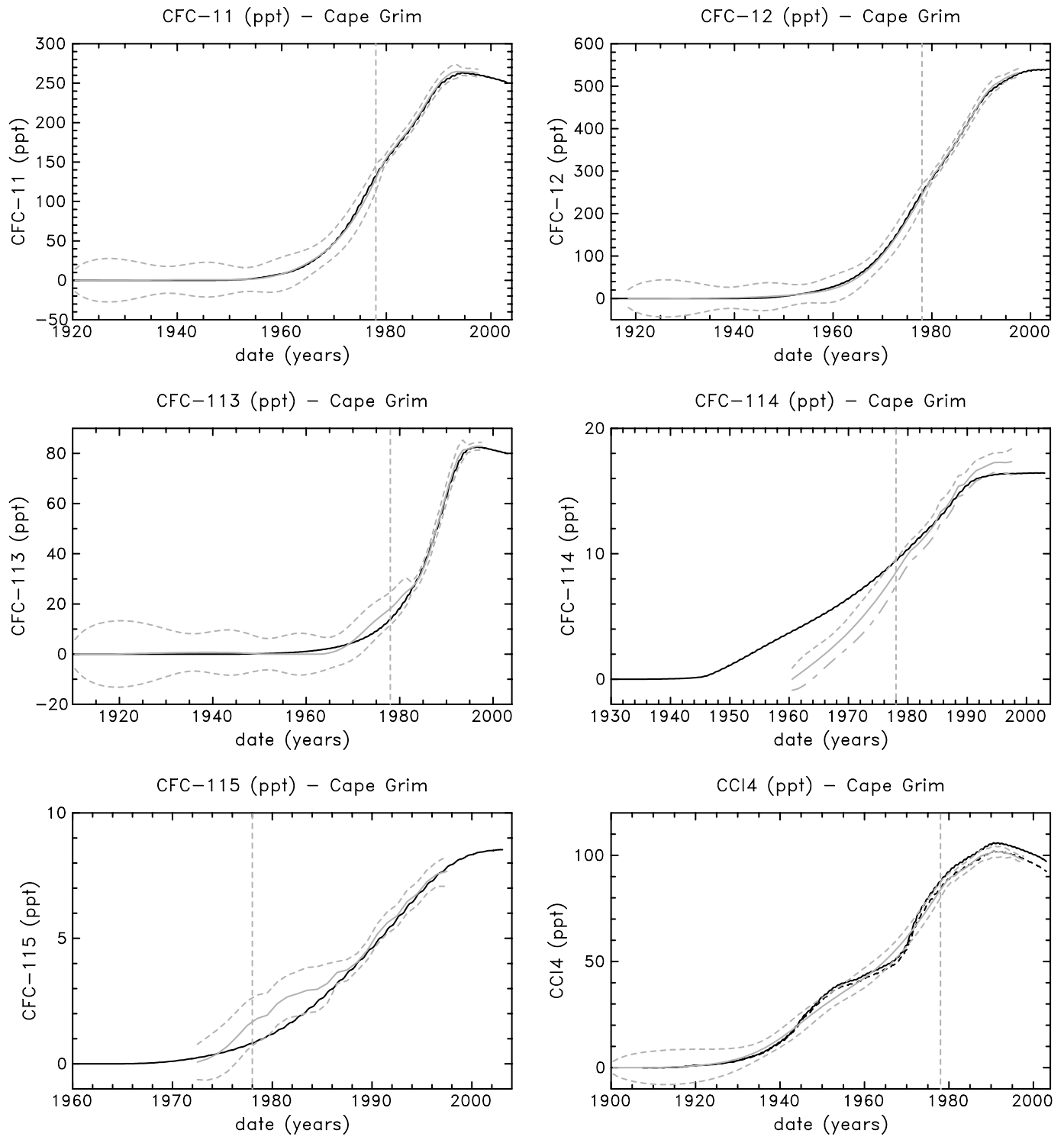

Fig. 8. Comparison of our concentration trends (in black) with the Sturrock et al. (2002) trends (in grey) at the latitude of Cape Grim.

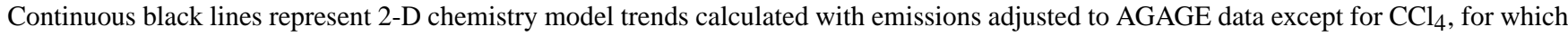
the AGAGE derived trend is represented by the black dashed line, whereas the black continuous line represents the trend calculated with emissions adjusted to ESRL data (this scale is more consistent with UEA data for $\mathrm{CCl}_{4}$ ). The grey lines represent the Sturrock et al. (2002) mean (continuous line), minimum and maximum (dashed lines) scenarios. The vertical grey line illustrates the start date of the Cape Grim air archive record used by Sturrock et al. (2002) to constrain their trends.

firns, where relatively shallow depth levels (before the steep part of the firn records) are affected. The data-model agreement is better with our emission based trend than with the Sturrock et al. (2002) trend for this gas. However, the effect of the difference between scenarios on CFC-113 depth profiles in firn is of similar magnitude as the uncertainty on CFC-113 diffusion coefficient used in firn models (see supplement http://www.atmos-chem-phys.net/9/3911/2009/ acp-9-3911-2009-supplement.pdf). The larger difference in scenarios for CFC-115, affecting the same age range (2025 years old air for the sites drilled before year 2000), also affect Devon Island results. At this site, the Sturrock et al. (2002) trend slightly improves the model-data agreement. The Sturrock et al. (2002) scenario somewhat overestimates the data at DML and Dome $\mathrm{C}$ whereas our scenario underestimates them, especially at Dome C. CFC-115 atmospheric history thus may have an intermediate behaviour between the two tested scenarios. Although the data dispersion is smaller 

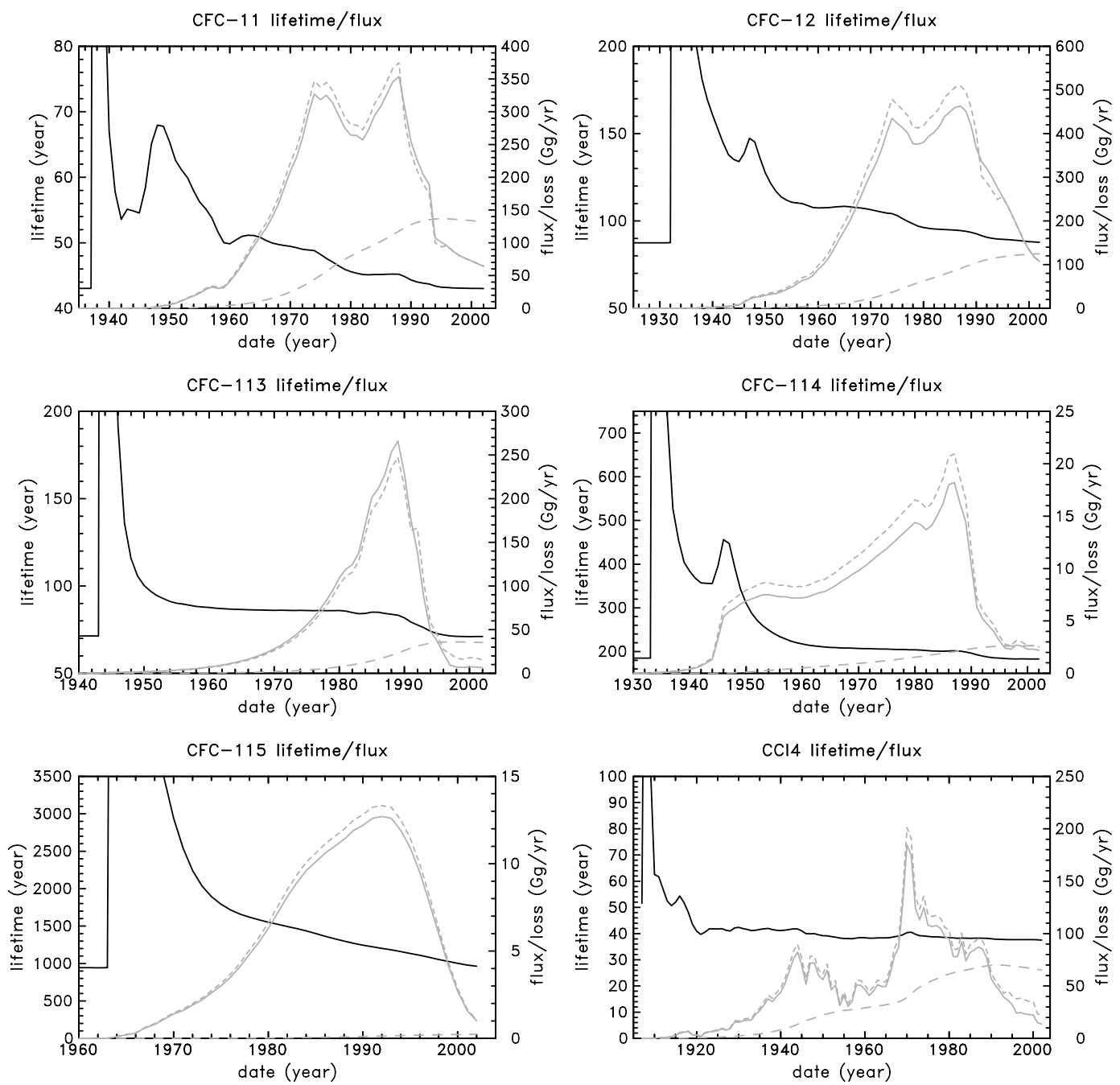

Fig. 9. Halocarbon emissions, atmospheric losses and lifetimes. Continuous grey lines: industrial inventory based emissions, short dashed lines: emissions corrected to fit recent atmospheric concentration trends, long dashed lines: atmospheric losses, black lines: atmospheric lifetimes (see Sect. 6.3).

for CFC-114 than for CFC-115, the model-data differences are larger for CFC-114 than for other CFCs, especially at Dome C. This trace gas is the only species for which our emission based scenario clearly differs from the envelope defined in Sturrock et al. (2002). The Sturrock et al. (2002) scenario improves the model data agreement at Arctic sites. The bottom part of Berkner record, showing a very pronounced slope change around $50 \mathrm{~m}$ depth, shows a small sensitivity to the large difference in scenarios. Both the Sturrock et al. (2002) and our scenario overestimate the DML and Dome C records in the depth range sensitive to 20-25 years old air. Although different, the two scenarios both induce important differences with Dome $\mathrm{C}$ data around $70-95 \mathrm{~m}$ depth. Thus no scenario can be considered as fully satisfactory. Overall, considering the large uncertainties on the CFC-114 and CFC-115 budgets (see Sect. 6.4), the Sturrock et al. (2002) scenarios derived from Law Dome firn data are mostly consistent with our emission based scenarios.

CFC-113 and CFC-114 concentrations at the deepest firn levels show a behaviour similar to CFC-11 and CFC-12: very low concentrations are measured at the bottom of all firn sites, with lower levels at Arctic sites (0.4-1 ppt CFC-113 and $0.2-0.8 \mathrm{ppt}$ CFC-114) than Antarctic sites (1.5-3.5 ppt CFC-113 and 0.7-1 ppt CFC-114). Our lowest CFC-115 values show very low concentrations at all sites: below the detection limit of NCAR measurements in the Arctic and $<0.25$ ppt in Antarctica, suggesting a later start of its atmospheric emissions than for CFC-114, which is confirmed by the emission data (Fig. 9). The Sturrock et al. (2002) CFC-114 and CFC-115 concentrations at Law Dome fall below their 0.1 ppt detection limit. Unlike other CFCs, CFC-113 shows similar concentrations near the firn-ice transition at Law Dome 

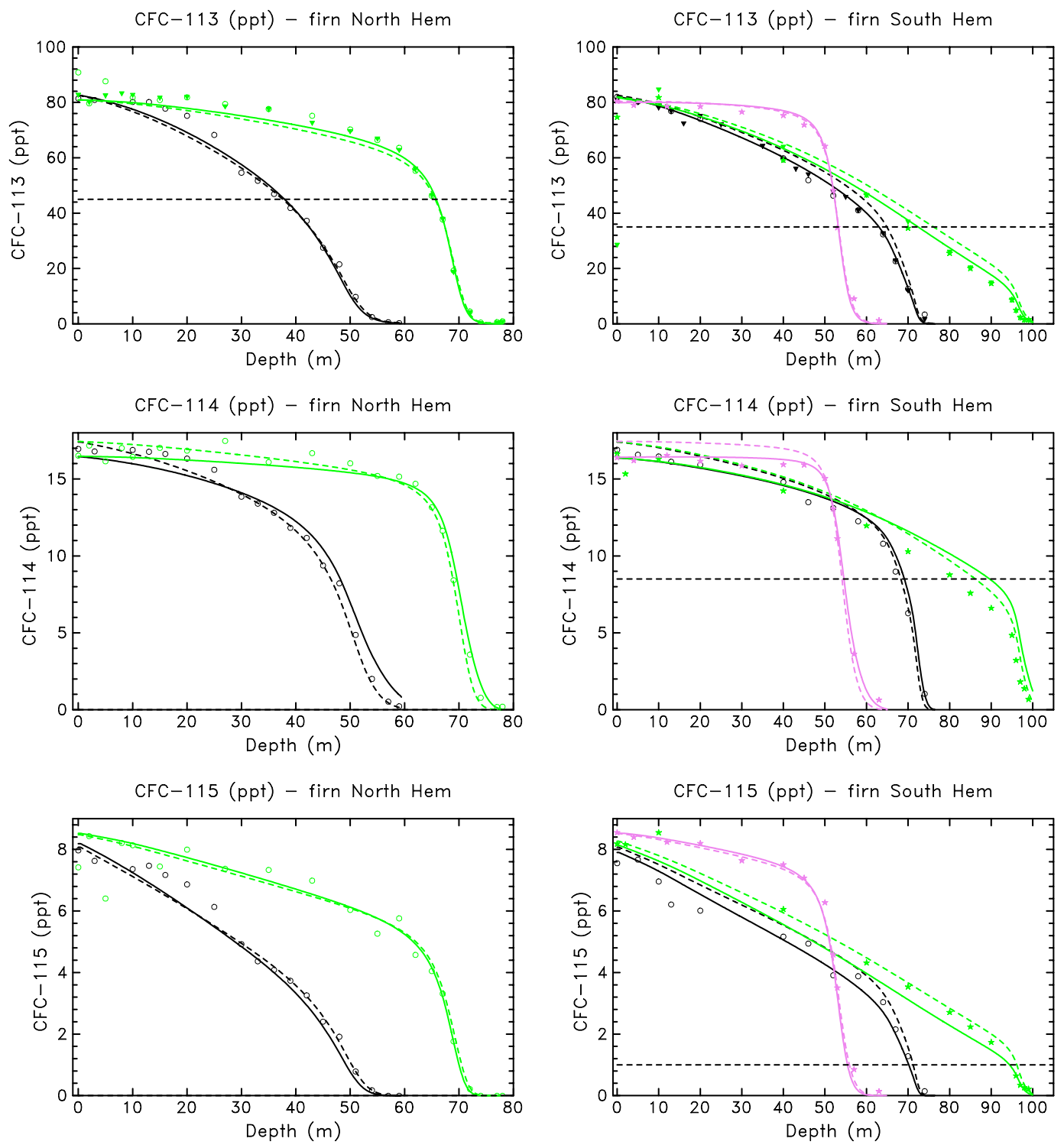

Fig. 10. Comparison of the firn model results with our emission-based scenarios (continuous lines) and the Sturrock et al. (2002) concentration-based mean scenarios (dashed lines) for CFCs 113, 114 and 115 with FIRETRACC and CRYOSTAT data (symbols). See Fig. 5 for drilling sites and measurement lab. symbols. The Sturrock et al. (2002) trend scenarios were extrapolated from 1997 to 2003 in order to simulate the North GRIP and Berkner firn data.

(0.38-0.74 ppt) and at our Arctic sites. Thus we suggest that the Sturrock et al. (2002) value might be somewhat overestimated. This would be qualitatively consistent with the overestimation of our DML and Dome C records by their scenario.

\subsubsection{Carbon tetrachloride $\left(\mathrm{CCl}_{4}\right)$}

$\mathrm{CCl}_{4}$ has the longest emission history, starting in 1908 (Fig. 9). On the other hand, experimental uncertainties are high for this species: our measured concentrations show a significant spreading, and the AGAGE-adjusted and ESRLadjusted chemistry model scenarios differ by 3.7 to $5 \%$ due to inter-calibration differences between the two records. Both these scenarios are represented in Fig. 11 because the ESRL-adjusted trend is more consistent with our observed concentrations, whereas the AGAGE-adjusted trend is consistent with the Sturrock et al. (2002) scenario. Although these last two scenarios are very similar (Fig. 8), the Dome C firn simulations show higher values around $90 \mathrm{~m}$ depth with the Sturrock et al. (2002) trend than with our AGAGE-adjusted scenario. This is likely due to higher val- 

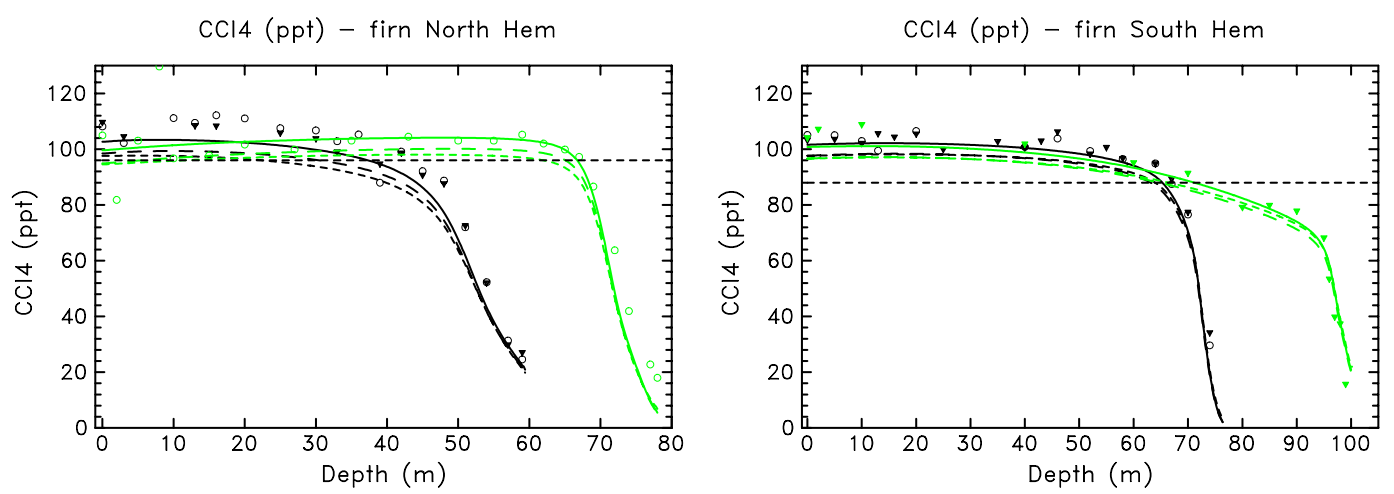

Fig. 11. Comparison of the firn model results with our emission-based scenarios (continuous lines: emissions adjusted to ESRL data, long dashed lines: emissions adjusted to AGAGE data) and the Sturrock et al. (2002) concentration-based mean scenarios (short dashed lines) for $\mathrm{CCl}_{4}$ with FIRETRACC and CRYOSTAT data (symbols). See Fig. 5 for drilling sites and measurement lab. symbols. There is no reliable $\mathrm{CCl}_{4}$ record at Berkner Island.
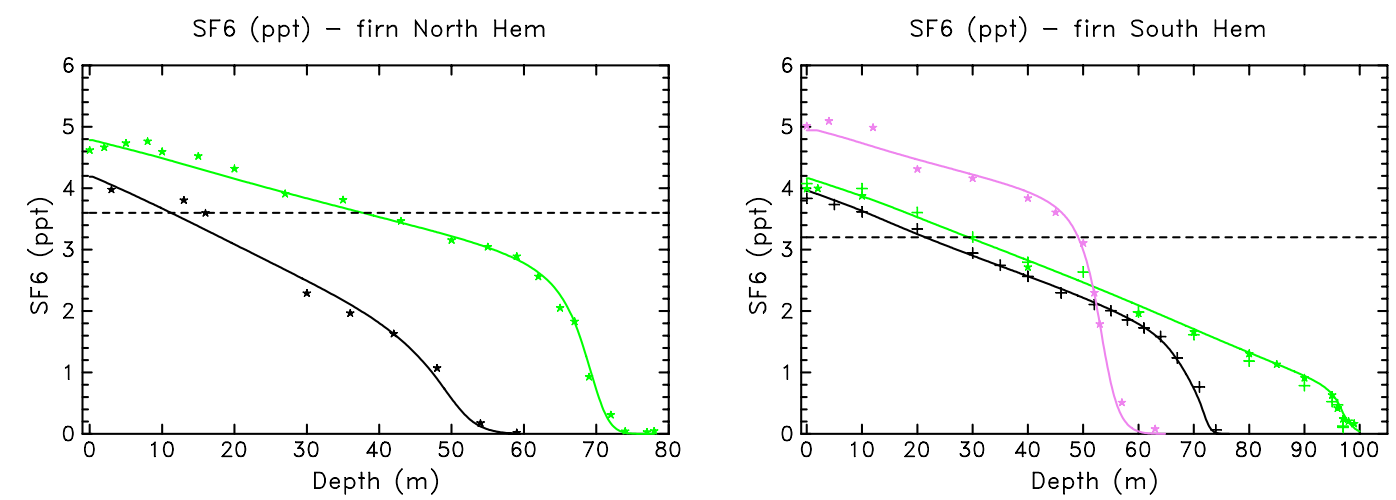

Fig. 12. Comparison of the firn model results (continuous lines) for $\mathrm{SF}_{6}$ with FIRETRACC and CRYOSTAT data (symbols). Measurements made at UEA are shown as stars, those made at MPI (Sturges et al., 2000; FIRETRACC, 2007) as plus signs. Drilling sites representation: see Fig. 5.

ues in the smooth Sturrock et al. (2002) scenario around 1965-1970 (Fig. 8). Taking into account the rather high firn data dispersion, our ESRL-adjusted scenario is globally consistent with the data except at Devon Island. We should remember that the Devon Island firn contains numerous refrozen melt layers which may affect its diffusivity (especially around $27 \mathrm{~m}$ depth, see Sect. 5). The $\mathrm{CCl}_{4}$ atmospheric record shows a pronounced maximum around 1990 (see supplement http://www.atmos-chem-phys.net/9/ 3911/2009/acp-9-3911-2009-supplement.pdf). The modeldata discrepancies in the Devon Island firn may result from an incorrect modelling of this feature due to higher uncertainties in the diffusivity at this site.

This early-emitted gas shows higher concentrations at the firn bottom than CFCs (18-35 ppt). Non zero $\mathrm{CCl}_{4}$ levels were also obtained by Butler et al. (1999) and Sturrock et al. (2002). Our atmospheric scenarios start with zero concentrations in 1907 and also lead to non zero modelled concentra- tions at the last measurement depths in the firn for all sites. Taking into account the uncertainties on the deep firn data and modelling discussed in Sect. 5, the overall consistency between the model and measured concentrations indicates that an atmospheric scenario with null $\mathrm{CCl}_{4}$ concentrations before 1908 can account for the measurements in firn. However, the high uncertainties on the $\mathrm{CCl}_{4}$ lifetime and budget (Sect. 6.3 and Sect. 6.4) preclude a quantification of $\mathrm{CCl}_{4}$ natural versus anthropogenic sources using our firn air data and models. Performing $\mathrm{CCl}_{4}$ measurements in ice cores is likely the most direct way of better constraining the preindustrial $\mathrm{CCl}_{4}$ concentration.

\subsubsection{Sulphur hexafluoride $\left(\mathrm{SF}_{6}\right)$}

As for CFC-11 and CFC-12 (Fig. 5) our model and $\mathrm{SF}_{6}$ concentration measurements show an excellent agreement at our five firn drilling sites (Fig. 12). Such a good agreement is 


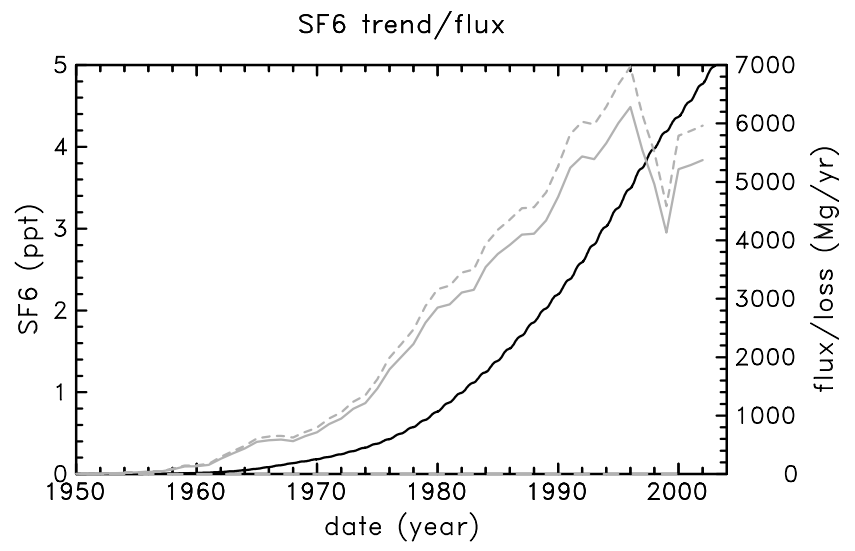

Fig. 13. $\mathrm{SF}_{6}$ concentration trends at the latitude of Cape Grim (in black) and emission scenarios (in grey) constructed from industrial inventories (continuous line, see Sect. 2.1), and corrected to fit the ESRL atmospheric record (dashed line).

obtained only if a stabilization of $\mathrm{SF}_{6}$ emissions in 19972002 (Fig. 13) is taken into account. Maiss and Brenninkmeijer (2000) observed a slope reduction in the $\mathrm{SF}_{6}$ atmospheric trend at Izana after 1996-1997, which suggest a $27 \%$ reduction in $\mathrm{SF}_{6}$ emissions. Smythe (2004) inventoried sales data from 7 major companies and conclude that a 33\% decrease in $\mathrm{SF}_{6}$ sales occurred in 1996-1999, followed by a $27 \%$ increase in 1999-2003. Smythe (2004) data were used to extrapolate the EDGAR (2007) emission trend from 1996 to 2003 (Fig. 13). This emission scenario had to be increased by $11 \%$ to reach ESRL $\mathrm{SF}_{6}$ concentration levels in 1995-2002, and model/data agreement on the recent slope of the trend could be reached (see supplement http://www.atmos-chem-phys.net/9/3911/2009/ acp-9-3911-2009-supplement.pdf). In the firn, an emission scenario which does not take into account a decrease in $\mathrm{SF}_{6}$ emissions around 1997-1999 would simulate correctly the firn data at the sites drilled in 2002-2003 but underestimate the upper firn $\mathrm{SF}_{6}$ data at the sites drilled in 1998-1999.

Our modelled $\mathrm{SF}_{6}$ trend (Fig. 13) is consistent with the trend derived by Maiss et al. (1996) from the Cape Grim air archive and atmospheric measurements although slightly overestimating it (by less than $0.2 \mathrm{ppt}$, see supplement http://www.atmos-chem-phys.net/9/3911/2009/ acp-9-3911-2009-supplement.pdf). It is also qualitatively consistent with those calculated by Butler et al. (1999); Sturges et al. (2000) with similar methodologies.

$\mathrm{SF}_{6}$ concentrations measured at the deepest firn sampling level range between 0.03 and $0.05 \mathrm{ppt}$ at Arctic sites and $0.09-0.18$ ppt at Antarctic sites. Similarly low concentrations were measured by Butler et al. (1999). A small natural $\mathrm{SF}_{6}$ source from crustal degassing has been identified (e.g. Deeds et al., 2008, and references therein). Deeds et al. (2008) estimate the total lithospheric flux of $\mathrm{SF}_{6}$ to be 13-
$80 \mathrm{~kg} / \mathrm{yr}$, which would sustain an atmospheric equilibrium concentration of 0.0004-0.0098 ppt with an $\mathrm{SF}_{6}$ lifetime of 800-3200 years. To our knowledge, the lowest $\mathrm{SF}_{6}$ concentration measured in firn air is 0.0063 ppt at Law Dome (Vollmer and Weiss, 2002). Our North GRIP record indicates a stabilization of $\mathrm{SF}_{6}$ concentrations in the $74-78 \mathrm{~m}$ depth range, however the suspicion of some contamination at $78 \mathrm{~m}$ depth (Sect. 4) and our detection limits (Sect. 5) preclude a firm estimate of the pre-industrial $\mathrm{SF}_{6}$ concentration from this site. Our North-GRIP data suggest that future high-precision $\mathrm{SF}_{6}$ measurements in central Greenland firn air could help confirming the Law Dome result.

\subsection{Halocarbon lifetimes}

Atmospheric lifetimes are often considered as constants. Locally (or in box models), lifetime is defined as the species concentration (e.g. in mol/ $\mathrm{cm}^{3}$ ) divided by its chemical loss (e.g. in $\mathrm{mol} / \mathrm{cm}^{3} / \mathrm{s}$ ). As the chemical loss rate is always proportional to the species concentration, the above ratio can be simplified and the local lifetime is independent from the species concentration. However, atmospheric chemical loss rates undergo temporal (e.g. in relation to day/night cycles) as well as spatial (e.g. in relation with the UV increase with altitude) variations. In chemistry models, which explicitly calculate atmospheric losses of chemical species, lifetimes are calculated as the global average concentration divided by the global average loss. Our target gases are destroyed only in the middle atmosphere, thus their lifetimes in the troposphere are virtually infinite. Since these gases are emitted at the ground, it takes them about a decade to reach the stratosphere where they are destroyed. This effect is visible in Fig. 9: the lifetimes show out of scale values at the beginning of the species emissions. Once halocarbons have reached their destruction region, their lifetimes decrease but remain sensitive to temporal changes in their emissions (with delay) (Fig. 9). Species destroyed in the troposphere (in the vicinity of their emission regions), such as methane or hydrogenated CFC substitutes do not exhibit such temporal variations of their lifetimes.

CFCs are commonly modelled without an explicit calculation of their lifetimes, but by imposing a homogeneous and constant loss rate based on literature values of their lifetimes. For example, this is the case in tropospheric models which use CFCs as transport tracers. In order to evaluate the effect of halocarbon lifetime variations on their concentration trends, three test simulations were performed. The first simulation aimed at evaluating the equilibrium lifetimes of our target species. The model was initialized with homogeneous halocarbon concentrations and run for 100 years with zero halocarbon emissions. In their destruction region, the local halocarbon lifetimes are much shorter than their global average lifetimes, thus the results stabilize rapidly. This is illustrated by the constant lifetimes obtained before the start of emissions in Fig. 9. In the second simulation, our halocarbon 


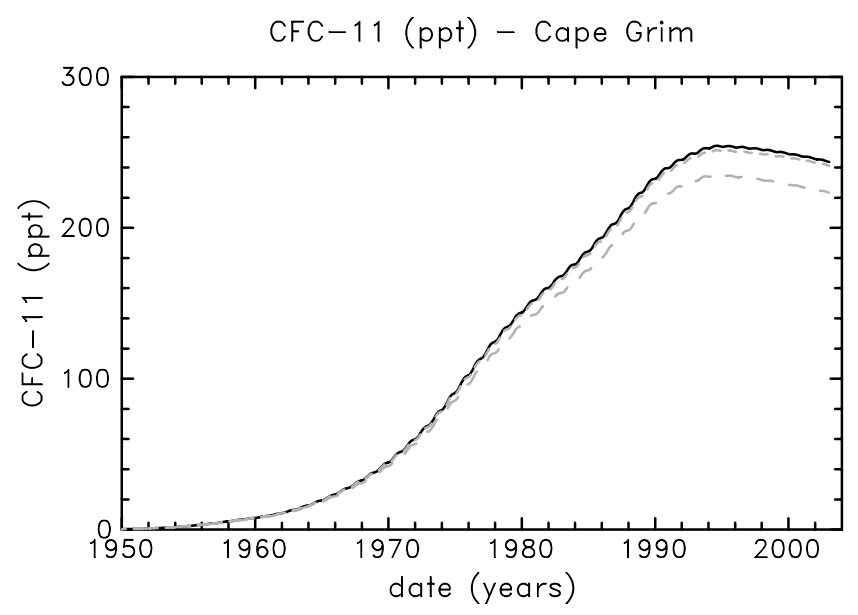

Fig. 14. Impact of spatial and temporal lifetime changes on CFC11 concentration trend. Continuous line: reference concentration trend. Long dashed line: concentration calculated with a constant and homogeneous lifetime (equilibrium lifetime). Short dashed line: concentration calculated by imposing the equilibrium lifetime as a scaling factor to the calculated CFC-11 sink.

loss rates were calculated as the inverse of the above equilibrium lifetimes times their concentration, thus imposing constant and homogeneous lifetimes. Finally, in order to separate the effects of spatial and temporal lifetime variations, a third simulation was performed: the chemical losses were calculated, and then rescaled so that the global average loss is consistent with the equilibrium lifetime. This suppresses the temporal changes in lifetimes while preserving their spatial structure. The results for CFC-11 are shown in Fig. 14. The concentration trend calculated with our third test run remains close to the reference simulation. Thus the temporal changes in lifetimes, which mainly occur in the early stage of historical emissions, have a small impact on the concentration trend. On the other hand, imposing a spatially homogeneous lifetime (second test run) leads to a significant decrease in CFC-11 concentrations. Thus tropospheric models or transport models, which calculate CFC concentrations with imposed lifetimes can produce a significant bias. Similar results for other halocarbons are provided in the supplementary material (http://www.atmos-chem-phys.net/9/3911/ 2009/acp-9-3911-2009-supplement.pdf). They show that this bias is most important for the relatively short lived gases, which have the most important chemical loss at the time scale of our simulation, whereas it is negligible for the very long lived CFC-115.

Our modelled equilibrium lifetimes for CFC-11, CFC-12 and CFC-113 are roughly consistent with the recommendations from WMO (2007) (Table 4). The atmospheric loss of these major CFCs is mostly due to photodissociation. CFC-114 and CFC-115 show larger differences with recommended values, which were established by Ravishankara
Table 4. Comparison of our chemistry model lifetimes with recommended lifetimes from WMO (2007) ("Life. WMO"). "Life. eq." is the equilibrium chemical lifetime, "Life. photo." and "Life. $O\left({ }^{1} \mathrm{D}\right)$ " display the equilibrium lifetimes due to photodissociation only and $\mathrm{O}\left({ }^{1} \mathrm{D}\right)$ reaction only respectively. "Life. 1975" and "Life. 2002" are our transient modelled chemical lifetimes for these years. The WMO (2007) lifetime for $\mathrm{CCl}_{4}$ includes the effect of its oceanic loss.

\begin{tabular}{lllllll}
\hline Gas & $\begin{array}{l}\text { Life. } \\
\text { WMO }\end{array}$ & $\begin{array}{l}\text { Life. } \\
\text { eq. }\end{array}$ & $\begin{array}{l}\text { Life. } \\
\text { Photo. }\end{array}$ & $\begin{array}{l}\text { Life. } \\
\mathrm{O}\left({ }^{1} \mathrm{D}\right)\end{array}$ & $\begin{array}{l}\text { Life. } \\
1975\end{array}$ & $\begin{array}{l}\text { Life. } \\
2002\end{array}$ \\
\hline CFC-11 & 45 & 43 & 44 & 273 & 48 & 43 \\
CFC-12 & 100 & 88 & 91 & 351 & 103 & 88 \\
CFC-113 & 85 & 72 & 74 & 287 & 86 & 71 \\
CFC-114 & 300 & 186 & 224 & 411 & 205 & 183 \\
CFC-115 $^{11700}$ & 948 & 1540 & 2130 & 1793 & 965 \\
$\mathrm{CCl}_{4}$ & 26 & 38 & 38 & 200 & 39 & 38 \\
\hline
\end{tabular}

et al. (1993). More recent cross section data from Sander et al. (2006) were used for photodissociations, whereas the $\mathrm{O}\left({ }^{1} \mathrm{D}\right)$ reaction rates have not been re-evaluated and the recommended values are still from Ravishankara et al. (1993). Although the $85 \mathrm{~km}$ upper limit of our model is lower than the $116 \mathrm{~km}$ in Ravishankara et al. (1993) and we thus miss some non negligible processes such as the Lyman-alpha photodissociation of CFC-115, we obtain lower lifetimes (i.e. higher atmospheric losses) than Ravishankara et al. (1993). However, at the timescale of our simulations, chemical losses play a minor role on the budget of these very long lifetime gases (Fig. 9). Our chemical equilibrium lifetime for $\mathrm{CCl}_{4}$ is consistent with the 35 years WMO (2007) estimate. However these lifetimes do not take into account an important oceanic sink which reduces $\mathrm{CCl}_{4}$ lifetime to approximately 26 years, nor a more recently discovered soil sink which could be of similar magnitude (WMO, 2007). WMO (2007) suggests that such short lifetimes would be difficult to reconcile with emissions deduced from high frequency atmospheric measurements or lifetimes deduced from $\mathrm{CCl}_{4}$ meridional gradients. On the other hand, the long-term inventory-based emissions of $\mathrm{CCl}_{4}$ are not well constrained, and the overall sources/sinks balance is poorly understood for $\mathrm{CCl}_{4}$.

In 1975, long lived halocarbon emissions were still increasing or fairly close to their peak. Our modelled lifetimes for this period are higher than equilibrium lifetimes and generally closer to the recommended values. In 2002, halocarbon emissions had been strongly reduced and our model lifetimes are very close to their equilibrium values.

\subsection{Species budgets and budget uncertainties}

Because our long-lived target gases have slow destruction rates, their budgets have long been dominated by their emissions. Following the strong decrease of these emissions 
Table 5. Halocarbon and $\mathrm{SF}_{6}$ budget analysis. The first three columns provide estimates of uncertainties on emissions accumulated over time: WMO (2007) values (from Table 1-7) are compared with the difference between our inventory-based and adjusted emissions to fit the AGAGE and ESRL records. The uncertainties on losses are the WMO (2007) $\left(1 / \tau_{\min }-1 / \tau_{\max }\right) /\left(1 / \tau_{\text {best }}\right)$ calculated from Table $1-7$ (column WMO), and the maximum differences in our modelled cumulated losses when using kinetic and photochemical constants from the last three JPL evaluations (DeMore et al., 1997; Sander et al., 2003, 2006) (column JPL). Calibration uncertainties estimated by WMO (2007) are compared with the UEA-NCAR differences in our firn air samples. Concentration uncertainties show the impact on year 2002 concentrations of our emission corrections to adjust AGAGE and ESRL measurements. Finally the last two columns display our chemistry model best estimate of emissions and losses accumulated over time until 2002.

\begin{tabular}{|c|c|c|c|c|c|c|c|c|c|c|c|}
\hline \multirow[t]{2}{*}{ Gas } & \multicolumn{3}{|c|}{$\Delta$ Emission $(\%)$} & \multicolumn{2}{|c|}{$\Delta \operatorname{Loss}(\%)$} & \multicolumn{2}{|c|}{$\Delta$ Calibration $(\%)$} & \multicolumn{2}{|c|}{$\Delta$ Concentration $(\%)$} & \multicolumn{2}{|c|}{ Cumul. budg. $\left(10^{9} \mathrm{~kg}\right)$} \\
\hline & WMO & AGAGE & ESRL & WMO & JPL & WMO & UEA-NCAR & AGAGE & ESRL & Emission & Loss \\
\hline CFC-11 & 18 & +3.6 & +7.3 & 50 & $<2$ & $<2$ & +1 & +3.0 & +6.3 & 9.0 & 3.5 \\
\hline CFC-12 & 7.5 & +7.1 & +6.3 & 38 & $<1$ & $<2$ & +1.5 & +6.5 & +5.7 & 14.4 & 2.9 \\
\hline CFC- 113 & 8.4 & -2.4 & -2.3 & 43 & $<1$ & $<2$ & +1 & -2.0 & -1.8 & 3.3 & 0.6 \\
\hline CFC-114 & & +15 & +15 & - & $<0.5$ & & +20 & - & +14 & 0.59 & 0.07 \\
\hline CFC-115 & & - & +5.0 & - & $<0.2$ & & +20 & - & +4.9 & 0.25 & 0.003 \\
\hline $\mathrm{CCl}_{4}$ & 34 & - & +11 & 77 & $<1.5$ & $3-4$ & +6 & +6.4 & +11 & 4.9 & 2.8 \\
\hline $\mathrm{SF}_{6}$ & & - & +11 & - & - & & & - & +10.5 & 0.14 & 0.0005 \\
\hline
\end{tabular}

under the Montreal protocol, our results indicate that photochemical destruction exceeds emissions for most of these species (Fig. 9). This change occurred approximately in 1993 for CFC-11, 2001 for CFC-12, 1995 for CFC-113, and 1996 for $\mathrm{CFC}-114$. For the shorter lived $\mathrm{CCl}_{4}$, atmospheric destruction dominates known emissions since 1990, but photochemical destruction has been influential since the early 1950's (Fig. 9). This is consistent with the recent stabilization or decrease of atmospheric concentrations of this gas (WMO, 2007). On the other hand the budgets of the longest lived gases, CFC-115 and $\mathrm{SF}_{6}$, are still largely dominated by their emissions. For these two compounds, the comparison of our modelled concentration trends with measurements is thus mostly indicative of the reliability of emissions. It is not the case for the recent part of other species records, which progressively become mostly influenced by atmospheric losses and thus become controlled by the species lifetimes.

CFC-113 has the most reduced emissions, however an important increase in these emissions $(+140 \%$ after 1996) was needed to reconcile our model results with the recent observed trend in CFC-113. It reflects the fact that our initial model results showed a too strongly decreasing slope in recent years (Fig. 2). As chemical losses largely dominate emissions at that time (Fig. 9), this discrepancy could be due to a smaller bias in CFC-113 lifetime. A test simulation showed that a $40 \%$ reduction of its chemical losses during that period also fits the concentration data. CFC-113 lifetime is then 84 years (instead of 71 years) in 2002.

By contrast, no emission correction was needed for CFC11 and 12 after 1995 and 1994 respectively. This suggests that the lifetimes of these compounds are consistent with their recent trends. However, their emissions in 2002 are still equivalent to $48 \%$ of the CFC- 11 loss and $86 \%$ of CFC- 12 loss (Fig. 9). Thus we cannot firmly conclude on the consistency of major CFC lifetimes with their concentration trends.
We should note that the increasing difficulty in estimating CFC emissions due to the dominant role of non reporting countries (see Sect. 2.1) may limit our ability to validate CFC lifetimes with their trends in the future. $\mathrm{CCl}_{4}$ emissions were increased by $5 \%$ until 1993 and $25 \%$ afterwards in order to fit its concentration trend. A much larger increase would be required if its oceanic and soil sinks were taken into account. However, the overall consistency of our firn model results with $\mathrm{CCl}_{4}$ data suggests that the historical variations in $\mathrm{CCl}_{4}$ emissions are generally correct.

Table 5 summarizes budget uncertainties for our target gases. Calibration uncertainties play a minor role except for CFC-114 and CFC-115. Our estimates of uncertainties on emissions and concentrations are not independent: they both reflect the emission adjustments necessary to fit atmospheric measurements. These values vary from one gas to another, they are small $(<2.5 \%)$ for CFC-113, intermediate $(5-10 \%)$ for CFC-11, CFC-12 and CFC-115 and exceed $10 \%$ for CFC$114, \mathrm{CCl}_{4}$ and $\mathrm{SF}_{6}$. Our uncertainties on calibration and emissions are globally consistent with WMO (2007). The highest uncertainties reported in WMO (2007) concern the halocarbon lifetimes. In Table 5, they are expressed in terms of atmospheric losses. The main sink of our target halocarbons is photodissociation. Their cross sections have been re-evaluated several times over the last decade. We compared modelled CFC losses calculated with three different chemical schemes derived from DeMore et al. (1997); Sander et al. $(2003,2006)$. The differences obtained are always lower than $2 \%$. On the other hand, WMO (2007) large uncertainties on atmospheric losses for major CFCs (38-50\%) are based on somewhat older estimates derived from modelbased values (WMO, 1999) and stratospheric measurements performed in 1994 (Volk et al., 1997). Part of these values are probably inconsistent with the recent concentration trends, which are more dependent on loss processes, thus 


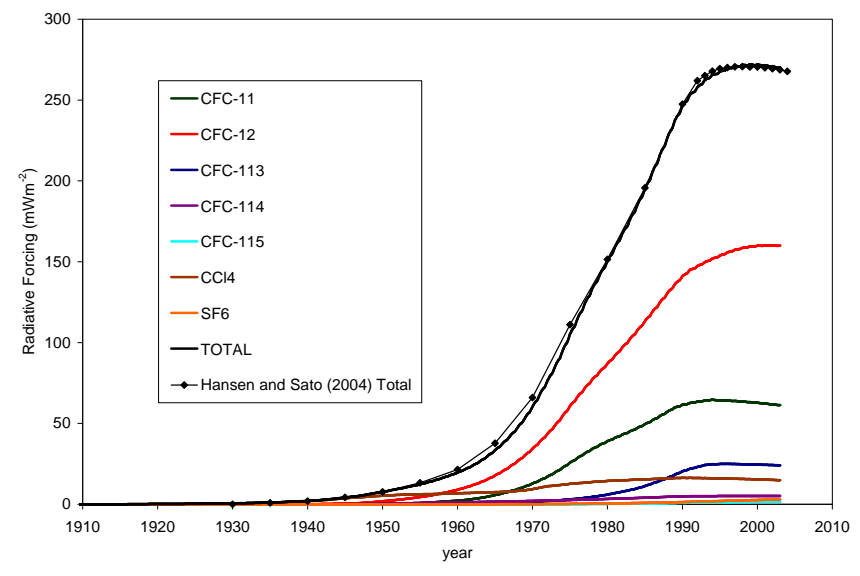

Fig. 15. Time series of radiative forcing for the seven gases in this study, together with the total forcing, compared with the forcing derived by Gohar and Shine (2007) using the Hansen and Sato (2004) concentration time series.

an updated evaluation of CFC lifetimes and lifetime uncertainties would improve the understanding of these species budgets. The very high WMO (2007) uncertainty for $\mathrm{CCl}_{4}$ $(77 \%)$ integrates the soil and oceanic sinks not taken into account in this study.

The last two columns in Table 5 provide our best estimates of the total emissions and losses accumulated over time between 1908 and 2002. Although atmospheric losses now equal or exceed annual emissions for most of our species, the previous domination of emissions still has a strong imprint on the accumulated budgets. This effect increases with the species lifetime: $57 \%$ of the emitted $\mathrm{CCl}_{4}$ has been destroyed whereas only $39 \%$ of CFC- $11,20 \%$ of CFC- 12 and $18 \%$ of CFC-113 had been eliminated from the atmosphere by 2002 . These percentages fall to $11 \%, 1 \%$, and $0.4 \%$ for the longer lived CFC-114, CFC-115 and $\mathrm{SF}_{6}$ respectively.

\subsection{Radiative forcing}

The concentrations generated by the 2-D chemistry model can be used to calculate radiative forcings. The method used here follows Gohar and Shine (2007), where radiative efficiencies $\left(\mathrm{W} \mathrm{m}^{-2} \mathrm{ppbv}^{-1}\right)$, together with the global-mean surface values derived from the model, are combined to give the forcings. Figure 15 shows the time-series of the radiative forcing for each of the 7 gases and the total. As expected, the total forcing in 2003 is dominated by CFC-12, which has the third largest radiative forcing among well mixed greenhouse gases (IPCC, 2007), followed by CFC-11, CFC-113 and $\mathrm{CCl}_{4}$ which also contribute significantly. The current contribution from the other gases: CFC-114, CFC-115 and $\mathrm{SF}_{6}$ is negligible, but their long lifetimes render their small contribution more permanent.
The 2-D model results constrained by the firn data gives improved confidence in the time variation of the forcing from these gases during the 20th century. As expected, given the linear relationship between the radiative forcings and concentrations of these gases, the forcing is seen to rise rapidly from the 1950s before starting to level off in the mid-1980s. For comparison, the forcings derived in Gohar and Shine (2007) using the time-series of gas concentrations used in the Goddard Institute of Space Studies climate model (Hansen and Sato, 2004, 2005) are also shown in Fig. 15. The CFC11 and CFC-12 concentration histories built by these authors are based on ESRL measurements for the instrumental period and industrial production data prior to 1978, together with lifetimes of 50 and 100 years for CFC-11 and CFC-12 respectively. Overall agreement in the total radiative forcing is very good for the instrumental period. Our slightly lower values in 1990-1995 are probably due to differences between the AGAGE and ESRL CFC-12 records for this period (Fig. 3). Higher differences, reaching around $6 \mathrm{mWm}^{-2}$, are obtained in the 1970s. However, differences in forcing for the individual gases can approach $15 \%$.

Although our target gases are responsible of only about $10 \%$ of the long-lived greenhouse gases radiative forcing $\left(2.63 \pm 0.26 \mathrm{Wm}^{-2}\right.$, IPCC (2007)), the control of the non$\mathrm{CO}_{2}$ greenhouse gas emissions plays an important role in efforts to avoid dangerous anthropogenic interference in the Earth's climate. As has been shown by Hansen and Sato (2004) and Velders et al. (2007), the control of CFCs emissions under the Montreal Protocol has played a significant role in reducing anthropogenic radiative forcing - indeed, as pointed out by Velders et al. (2007), the Montreal Protocol has likely had a greater influence than the Kyoto Protocol. As the Montreal Protocol has been successful in strongly reducing CFC emissions (Fig. 9), their future radiative impact should be increasingly dependent on their atmospheric loss rate (Sect. 6.4).

\section{Conclusions}

Polar firn is a large reservoir of old air, which allows for the measurement of numerous low concentration species. Trace gas measurements in firn air provide a unique tool to assess their concentration trends over the pre-instrumental period of the 20th century. The use of firn models allows the translation of firn-air records into atmospheric trends. Multi-species studies permit to better constrain the main model parameter: firn diffusivity, through the detection of systematic bias for a given depth range. On the other hand, multi-site studies better constrain the atmospheric trend scenarios, because their different characteristics (accumulation rate, temperature, etc.) lead to different trace gas age structures in firn. Globally, high accumulation and temperature sites provide results with best time resolution whereas low accumulation 
and temperature sites are sensitive to earlier variations in atmospheric trends.

Two kinds of approaches have been used in order to infer atmospheric concentration trends: firn model inversion techniques or "top-down" methods (e.g. Rommelaere et al., 1997; Sturrock et al., 2002) and emission-based scenarios used in direct firn models and compared with data or "bottomup" methods (e.g. Butler et al., 1999). Our study used the "bottom-up" approach with a full atmospheric chemistry model which further allows to discuss the lifetimes and budgets of our target species. Our best-fit scenarios are directly compared with the Sturrock et al. (2002) "top-down" scenarios. The two approaches show a remarkable agreement for CFC-11 and CFC-12. It is due to both the consistency of early major CFC emissions with the firn records, and the relative smoothness of these emissions which lead to smooth atmospheric scenarios that can be derived from a small number of firn air measurements. By contrast, the two approaches lead to somewhat different scenarios for CFC113, CFC-114, CFC-115 and $\mathrm{CCl}_{4}$. Our emission based scenario leads to a better fit of our CFC-113 firn data, whereas an intermediate trend between the "bottom-up" and "topdown" derived scenarios would best fit the CFC-115 data. A less satisfactory model/data agreement is achieved with either scenarios for $\mathrm{CFC}-114$ and $\mathrm{CCl}_{4}$, which have higher data dispersions and inter-calibration corrections, and insufficiently constrained budgets. However this scenario comparison shows that fairly small and old differences in the atmospheric trends (e.g. CFC-113) can leave an imprint in the firn, especially at low-accumulation sites. As for CFC-11 and CFC-12, an excellent model/data agreement is obtained for $\mathrm{SF}_{6}$, suggesting that the emissions of this very long lived gas are well constrained. However only an emission scenario which fits the slope reduction in the $\mathrm{SF}_{6}$ concentration trend around 1998-2002 can be consistent with both firn sites drilled in 1998-1999 and those sampled in 2002-2003. Improved estimates of halocarbon historical concentration trends might be derived in the future from a "top-down" approach (inverse modelling of firn) constrained with data from ideally all available firn air pumping sites. The comparison with "bottom-up" studies would then allow to better assess the uncertainties on the species budgets (i.e. emissions and/or lifetimes).

The low concentrations observed at the last depth levels of all firn sampling sites confirm that pre-industrial concentrations of our target compounds were small (WMO, 2007). The consistency between these data and simulated concentrations in firn further suggests that non-zero emissions in the early 20th century are not required to account for our firn air records. However, a full determination of pre-industrial concentrations of our target gases requires high precision measurements in ice cores.

Our chemistry model results show important temporal variations in $\mathrm{CFC}$ and $\mathrm{CCl}_{4}$ lifetimes. Such pollutants emitted at the Earth's surface and destroyed only in the strato- sphere have no chemical loss in the troposphere, therefore their lifetime is virtually infinite at the beginning of their emission, since their transport to the stratosphere requires several years before chemical destruction can begin. The trends and budgets of halocarbons destroyed in the stratosphere are often calculated using tropospheric-only models. In such cases, the chemical sinks are not calculated but a constant and homogeneous sink (the inverse of the equilibrium lifetime) is imposed in the whole atmosphere. Specific tests simulations showed that this can induce a significant bias on the $\mathrm{CFC}$ and $\mathrm{CCl}_{4}$ trends. Following the Montreal Protocol, the emissions of these ozone depleting substances have been strongly reduced, thus their trends and budgets are becoming increasingly dominated by their sinks. We believe that in order to better predict the ozone layer recovery, efforts should be made to update and reduce the large uncertainties on recommended CFC lifetimes. This would also improve the estimate of future radiative forcing by these gases.

Our results confirm that the budget histories of CFC-11, CFC-12, CFC-113, and $\mathrm{SF}_{6}$ are well understood. However, our emission-constrained CFC-113 scenario shows a too quickly decreasing trend over recent years. It could result either from a strong underestimation of its sources or a smaller overestimation of its losses. The long-lived CFC-115 emissions are reasonably consistent with the Cape Grim air archive data and firn air records. On the other hand, the CFC114 and $\mathrm{CCl}_{4}$ budgets and trends are still insufficiently understood. When accumulated over time, the total emissions still largely dominate the total losses for our target species, due to their long lifetimes and the overall strong rise of their emissions during the twentieth century.

Acknowledgements. We are grateful to Steve Montzka for his help at selecting the best data among the ESRL records and to Emmanuel Witrant for useful discussions about the mathematical and numerical aspects of firn models. We also thank the people involved in field campaigns and acquisition of data used in this study, especially Paul Begley, Carl Brenninkmeijer, Robert Mulvaney and Jakob Schwander. This work was funded by the CEC programmes: EUK2-CT2001-00116 (CRYOSTAT) and ENV4-CT97-0406 (FIRETRACC). It would not have been possible without the use of numerous data available in public databases, in particular: The FIRETRACC and CRYOSTAT data in BADC database (http://badc.nerc.ac.uk), AADC (http://data.aad.gov.au/aadc/portal), AFEAS (http://www.afeas.org), EDGAR (http://www.rivm.nl/edgar), AGAGE (http://cdiac.ornl.gov/ndps/alegage.html), ESRL (http://www.esrl.noaa.gov/gmd), NCEP (ftp://ftp.cpc.ncep. noaa.gov/ndacc/), JPL (http://jpldataeval.jpl.nasa.gov), and IUPAC (http://www.iupac-kinetic.ch.cam.ac.uk). We thank the people involved in the acquiring, analysis, and accessibility of these data. This work also benefited at Devon Island from the field support of the French Polar Institute (IFRTP), of R. Koerner and D. Fisher of the Geological Survey of Canada (Glaciology Section), and of the Polar Continental Shelf Project (Natural Resources Canada). The North GRIP project was directed and organized by the Department of Geophysics at the Niels Bohr Institute for Astronomy, Physics 
and Geophysics, University of Copenhagen. It was supported by Funding Agencies in Denmark (SNF), Belgium (FNRS-CFB), France (IFRTP and INSU/CNRS), Germany (AWI), Iceland (RannIs), Japan (MEXT), Sweden (SPRS), Switzerland (SNF) and the United States of America (NSF). The Berkner Island drilling was organized and conducted by the British Antarctic Survey with funding from the Natural Environmental Research Council (NERC). Firn air analysis at Dronning Maud Land and Dome C contribute to the European Project for Ice Coring in Antarctica (EPICA), a joint ESF/EC scientific programme, funded by the EC under the Environment and Climate Programme (1994-1998) (ENV4-CT95-0074) and by national contributions from Belgium, Denmark, France, Germany, Italy, the Netherlands, Norway, Sweden, Switzerland and the United Kingdom. The fieldwork at Dome C was also supported by the French Polar Institute (IFRTP) and the ENEA Antarctic Project (Italy). The page charges for this article were covered by the Copernicus - Institut National des Sciences de L'Univers (INSU) component of Centre National de la Recherche Scientifique (CNRS) contract.

Edited by: J. Burkholder

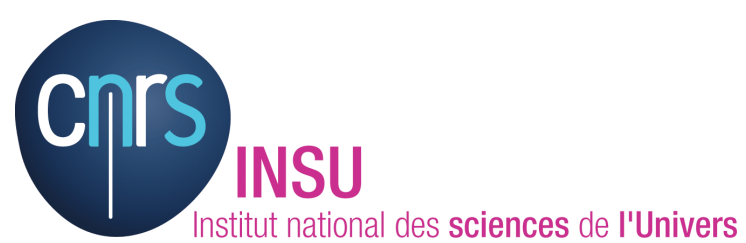

The publication of this article is financed by CNRS-INSU.

\section{References}

AFEAS: (Alternative Fluorocarbons Environmental Acceptability Study) Production and sales data available through 2004, http: //www.afeas.org/prodsales_download.html (last access: 1 March 2007), 2007.

Battle, M., Bender, Sowers, T., Tans, P. P., Butler, J. H., Elkins, J. W., Ellis, J. T., Conway, T., Zhang, N., Lang, P., and Clarke, A. D.: Atmospheric gas concentrations over the past century measured in air from firn at the South Pole, Nature, 383, 231235, 1996.

Brasseur, G., Hitchman, M. H., Walters, S., Dymek, M., Falise, E., and Pirre, M.: An interactive chemical dynamical radiative twodimensional model of the middle atmosphere, J. Geophys. Res., 95, 5639-5655, 1990.

Butler, J. H., Battle, M., Bender, M. L., Montzka, S. A., Clarke, A. D., Saltzman, E. S., Sucher, C. M., Severinghaus, J. P., and Elkins, J. W.: A record of atmospheric halocarbons during the twentieth century from polar firn air, Nature, 399, 749-755, 1999.

CRYOSTAT: CRYOspheric STudies of Atmospheric Trends in stratospherically and radiatively important gases (CRYOSTAT), http://badc.nerc.ac.uk/data/cryostat (last access: 31 July 2008), 2007.

Deeds, D. A., Vollmer, M. K., Kulongoski, J. T., Miller, B. R., Mühle, J., Harth, C. M., Izbicki, J. A., Hilton, D. R., and Weiss, R. F.: Evidence for crustal degassing of $\mathrm{CF}_{4}$ and $\mathrm{SF}_{6}$ in Mojave
Desert groundwaters, Geochim. Cosmochim. Ac., 72, 999-1013, doi:10.1016/j.gca.2007.11.027, 2008.

DeMore, W. B., Sander, S. P., Golden, D. M., Hampson, R. F., Kurylo, M. J., Howard, C. J., Ravishankara, A. R., Kolb, C. E., and Molina, M. J.: Chemical Kinetics and Photochemical Data for Use in Stratospheric Modeling, Evaluation Number 12, vol. 97-4 of JPL Publication, Jet Propulsion Laboratory, Pasadena, California, USA, 1997.

EDGAR: (The EDGAR V2.0, V3.2 and V3.2 FT2000 databases), http://www.rivm.nl/edgar/model/ (last access: 22 November 2007), 2007.

Elkins, J. W., Butler, J. H., Hurst, D. F., Montzka, S. A., Moore, F. L., Thompson, T. M., and Hall, B. D.: Halocarbons and other Atmospheric Trace Species Group/Climate Monitoring and Diagnostics Laboratory (HATS/CMDL), http://www.esrl.noaa.gov/ gmd/hats (last access: 16 November 2007), 1998.

Engel, A., Schmidt, U., and McKenna, D.: Stratospheric trends of CFC-12 over the past two decades: Recent observational evidence of declining growth rates., Geophys. Res. Lett., 25, 33193322, 1998.

Fabre, A., Barnola, J.-M., Arnaud, L., and Chappellaz, J.: Determination of gas diffusivity in polar firn: comparison between experimental measurements and inverse modeling, Geophys. Res. Lett., 27, 557-560, 2000.

FIRETRACC: Firn Record of Trace Gases Relevant to Atmospheric Chemical Change over 100 yrs (FIRETRACC/100), http://badc. nerc.ac.uk/data/firetracc (last access: 31 July 2008), 2007.

Gilliland, E. R.: Diffusion coefficients in gaseous systems, Ind. Engng. Chem., 26, 681-685, 1934.

Gohar, L. K. and Shine, K. P.: Equivalent $\mathrm{CO}_{2}$ and its use in understanding the climate effects of increased greenhouse gas concentrations, Weather, 62, 307-311, doi:10.1002/wea.103, 2007.

Hansen, J. and Sato, M.: Greenhouse gas growth rates, Proc. Natl. Acad. Sci., 101, 16109-16114, doi:10.1073/pnas.0406982101, 2004.

Hansen, J. and Sato, M.: Forcings in GISS Climate Model: WellMixed Anthropogenic Greenhouse Gases, http://data.giss.nasa gov/modelforce/ghgases (last access: 15 October 2008), 2005.

Happell, J. D. and Roche, M. P.: Soils: A global sink of atmospheric carbon tetrachloride, Geophys. Res. Lett., 30, 1088, doi:10.1029/ 2002GL015957, 2003.

IPCC: Climate Change 2001: The Scientific Basis, Contribution of Working Group I to the Third assessment report of the Intergovernmental Panel on Climate Change, Cambridge, UK and New York, USA, 2001.

IPCC: Climate Change 2007: The Physical Science Basis. Contribution of Working Group I to the Fourth Assessment Report of the Intergovernmental Panel on Climate Change, Cambridge University Press, United Kingdom and New York, NY, USA, http://www.ipcc.ch/ipccreports/assessments-reports.htm, 2007.

IUPAC: (International Union of Pure and Applied Chemistry Subcommittee for Gas Kinetic Data Evaluation) Evaluated kinetic data, http://www.iupac-kinetic.ch.cam.ac.uk (last access: September 2006), 2006.

Jacob, D. J., Prather, M. J., Wolfsy, S. C., and McElroy, M. B.: Atmospheric distribution of ${ }^{85} \mathrm{Kr}$ simulated with a general circulation model, J. Geophys. Res., 92, 6614-6626, 1987.

Levin, I. and Hesshaimer, V.: Refining of atmospheric transport model entries by the globally observed passive tracer distribu- 
tions of ${ }^{85}$ krypton and sulphur hexafluoride $\left(\mathrm{SF}_{6}\right)$, J. Geophys. Res., 101, 16745-16755, 1996.

Machida, T., Nakazawa, T., Fujii, Y., Aoki, S., and Watanabe, O.: Increase in the atmospheric nitrous oxide concentration during the last 250 years, Geophys. Res. Lett., 22, 2921-2924, 1995.

MacFarling Meure, C., Etheridge, D., Trudinger, C., Steele, P., Langenfelds, R., van Ommen, T., Smith, A., and Elkins, J.: Law Dome $\mathrm{CO}_{2}, \mathrm{CH}_{4}$ and $\mathrm{N}_{2} \mathrm{O}$ ice core records extended to 2000 years BP, Geophys. Res. Lett., 33, L14810, doi:10.1029/ 2006GL026152, 2006.

Madronich, S.: Environmental effects of UV (ultraviolet) radiation, chap. UV radiation in the natural and perturbed atmosphere, CRC Press, Boca Raton, 17-69, 1993.

Maiss, M. and Brenninkmeijer, C. A. M.: Atmospheric $\mathrm{SF}_{6}$ : Trends, Sources, and Prospects, Environ. Sci. Technol., 32, 3077-3086, 1998.

Maiss, M. and Brenninkmeijer, C. A. M.: A reversed trend in emissions of $\mathrm{SF}_{6}$ into the atmosphere?, in: Non $\mathrm{CO}_{2}$ greenhouse gases: scientific understanding, control and implementation, Proc. 2nd international symp., edited by: van Ham, J. V., Baede, A. P. M., Meyer, L. A., and Ybema, R., Kluwer Academic Publishers, Dordrecht, Noordwijkerhout, The Netherlands, 199204, 2000.

Maiss, M., Steele, L. P., Francey, R. J., Fraser, P. J., Langenfelds, R. L., Trivett, N. B. A., and Levin, I.: Sulfur hexafluoride - a powerful new atmospheric tracer, Atmos. Environ., 30, 16211629, 1996.

Martinerie, P., Raynaud, D., Etheridge, D. M., Barnola, J.-M., and Mazaudier, D.: Physical and climatic parameters which influence the air content in polar ice, Earth Planet. Sci. Lett., 112, 1-13, 1992.

Martinerie, P., Brasseur, G. P., and Granier, C.: The chemical composition of ancient atmospheres: A model study constrained by ice core data, J. Geophys. Res., 100, 14291-14304, 1995.

McCulloch, A., Ashford, P., and Midgley, P. M.: Historic emissions of fluorotrichloromethane (CFC-11) based on a market survey, Atmos. Environ., 35, 4387-4397, 2001.

McCulloch, A., Midgley, P. M., and Ashford, P.: Releases of refrigerant gases (CFC-12, HCFC-22 and HFC-134a) to the atmosphere, Atmos. Environ., 37, 889-902, 2003.

Montzka, S. A., Butler, J. H., Elkins, J. W., Thompson, T. M., Clarke, A. D., and Lock, L. T.: Present and future trends in the atmospheric burden of ozone-depleting halogens, Nature, 398, 690-694, 1999.

NCEP: Network for the Detection of Atmospheric Composition Change (NDACC) database, ftp://ftp.cpc.ncep.noaa.gov/ndacc/ (last access: 28 March 2006), 2006.

Oram, D. E.: Trends of long-lived anthropogenic halocarbons in the Southern Hemisphere and model calculations of global emissions, Ph.D. thesis, University of East Anglia, Norwich, UK, 1999.

Perry, R. H. and Chilton, C. H.: Chemical engineers handbook, 5th Ed., McGraw-Hill, New York, USA, 1973.

Prinn, R. G., Cunnold, D. M., Rasmussen, R., Simmonds, P. G., Alyea, F. N., Crawford, A., Fraser, P. J., and Rosen, R.: Atmospheric emissions and trends of nitrous oxide deduced from ten years of ALE-GAGE data, J. Geophys. Res., 95, 18369-18385, 1990.

Prinn, R. G., Weiss, R. F., Fraser, P. J., Simmonds, P. G., Cun- nold, D. M., Alyea, F. N., O’Doherty, S., Salameh, P., Miller, B. R., Huang, J., Wang, R. H. J., Hartley, D. E., Harth, C., Steele, L. P., Sturrock, G., Midgley, P. M., and McCulloch, A.: A history of chemically and radiatively important gases in air deduced from ALE/GAGE/AGAGE, J. Geophys. Res., 105, 17751-17792, 2000.

Randel, W. J.: Global atmospheric circulation statistics, 1000-1mb, vol. TN-295 of NCAR Tech. Note, Natl. Cent. For Atmos. Res., Boulder, Colorado, USA, 1987.

Ravishankara, A. R., Solomon, S., Turnipseed, A. A., and Warren, R. F.: Atmospheric lifetimes of long-lived halogenated species, Science, 259, 194-199, 1993.

Rommelaere, V., Arnaud, L., and Barnola, J.-M.: Reconstructing recent atmospheric trace gas concentrations from polar firn and bubbly ice data by inverse methods, J. Geophys. Res., 102, 30069-30083, 1997.

Sander, S. P., Friedl, R. R., Golden, D. M., Kurylo, M. J., Huie, R. E., Orkin, V. L., Moortgat, G. K., Ravishankara, A. R., Kolb, C. E., Molina, M. J., and Finlayson-Pitts, B. J.: Chemical Kinetics and Photochemical Data for Use in Atmospheric Studies Evaluation Number 14, vol. 02-25 of JPL Publication, Jet Propulsion Laboratory, Pasadena, California, USA, 2003.

Sander, S. P., Friedl, R. R., Golden, D. M., Kurylo, M. J., Moortgat, G. K., Keller-Rudek, H., Wine, P. H., Ravishankara, A. R., Kolb, C. E., Molina, M. J., Finlayson-Pitts, B. J., Huie, R. E., and Orkin, V. L.: Chemical Kinetics and Photochemical Data for Use in Atmospheric Studies Evaluation Number 15, vol. 06-2 of JPL Publication, Jet Propulsion Laboratory, Pasadena, California, USA, http://jpldataeval.jpl.nasa.gov, 2006.

Schwander, J., Stauffer, B., and Sigg, A.: Air mixing in firn and the age of the air at pore close-off, Ann. Glaciol., 10, 141-145, 1988.

Schwander, J., Barnola, J.-M., Andrie, C., Leuenberger, M., Ludin, A., Raynaud, D., and Stauffer, B.: The age of the air in the firn and ice at Summit, Greenland, J. Geophys. Res., 98, 2831-2838, 1993.

Simmonds, P. G., Cunnold, D. M., Weiss, R. F., Prinn, R. G., Fraser, P. J., McCulloch, A., Alyea, F. N., and O'Doherty, S.: Global trends and emission estimates of $\mathrm{CCl}_{4}$ from in situ background observations from July 1978 to June 1996, J. Geophys. Res., 103, 16017-16027, 1998.

Smythe: Trends in $\mathrm{SF}_{6}$ Sales End-Use Applications: 1961-2003, http://www.epa.gov/highgwp/electricpower-sf6/documents/ conf04_smythe.pdf (last access: 31 July 2008), 2004.

Sturges, W. T., Wallington, T. J., Hurley, M. D., Shine, K. P., Sihra, K., Engel, A., Oram, D. E., Penkett, S. A., Mulvaney, R., and Brenninkmeijer, C. A. M.: A Potent Greenhouse Gas Identified in the Atmosphere: $\mathrm{SF}_{5} \mathrm{CF}_{3}$, Science, 289, 611-613, 2000.

Sturges, W. T., McIntyre, H. P., Penkett, S. A., Chappellaz, J., Barnola, J.-M., Mulvaney, R., Atlas, E., and Stroud, V.: Methyl bromide, other brominated methanes, and methyl iodide in polar firn air, J. Geophys. Res., 106, 1595-1606, 2001.

Sturrock, G. A., Etheridge, D. M., Trudinger, C. M., Fraser, P. J., and Smith, A. M.: Atmospheric histories of halocarbons from analysis of Antarctic firn air: Major Montreal Protocol species, J. Geophys. Res., 107, 4765, doi:10.1029/2002JD002548, 2002.

Trudinger, C. M., Enting, I. G., Etheridge, D. M., Francey, R. J., Levchenko, V. A., and Steele, L. P.: Modeling air movement and bubble trapping in firn, J. Geophys. Res., 102, 6747-6763, 1997. Trudinger, C. M., Etheridge, D. M., Rayner, P. J., Enting, I. G., 
Sturrock, G. A., and Langenfelds, R. L.: Reconstructing atmospheric histories from measurements of air composition in firn, J. Geophys. Res., 107, 4780, doi:10.1029/2002JD002545, 2002.

Velders, G. J. M., Andersen, S. O., Daniel, J. S., Fahey, D. W., and McFarland, M.: The importance of the Montreal Protocol in protecting climate, Proc. Natl. Acad. Sci., 104, 4814-4819, doi:10.1073/pnas.0610328104, 2007.

Volk, C. M., Elkins, J. W., Fahey, D. W., Dutton, G. S., Gilligan, J. M., Loewenstein, M., Podolske, J. R., Chan, K. R., and Gunson, M. R.: Evaluation of source gas lifetimes from stratospheric observations, J. Geophys. Res., 102, 25543-25564, 1997.

Vollmer, M. K. and Weiss, R. F.: Simultaneous determination of sulfur hexafluoride and three chlorofluorocarbons in water and air, Mar. Chem., 78, 137-148, 2002.

Wang, W.-C., Shi, G.-Y., and Kiehl, J. T.: Incorporation of the thermal radiative effect of $\mathrm{CH}_{4}, \mathrm{~N}_{2} \mathrm{O}, \mathrm{CF}_{2} \mathrm{Cl}_{2}$, and $\mathrm{CFCl}_{3}$ into the National Center for Atmospheric Research Community Climate Model, J. Geophys. Res., 96, 9097-9103, 1991.

WMO: Scientific Assessment of Ozone Depletion: 1998, Global Ozone Research and Monitoring Project, Report No. 44, World Meteorological Organization, Geneva, 1999.

WMO: Scientific Assessment of Ozone Depletion: 2006. Global Ozone Research and Monitoring Project - Report No. 50, World Meteorological Organization, Geneva, http://ozone.unep. org/Publications, 2007.
Worton, D. R., Sturges, W. T., Gohar, L. K., Shine, K. P., Martinerie, P., Oram, D. E., Humpfrey, S. P., Begley, P., Gunn, L., Barnola, J.-M., Schwander, J., and Mulvaney, R.: Atmospheric Trends and Radiative Forcings of $\mathrm{CF}_{4}$ and $\mathrm{C}_{2} \mathrm{~F}_{6}$ Inferred from Firn Air, Environ. Sci. Technol., 41, 2184-2189, 2007.

Yvon-Lewis, S. A. and Butler, J. H.: Effect of oceanic uptake on atmospheric lifetimes of selected trace gases, J. Geophys. Res., 107, 4414, doi:10.1029/2001JD001267, 2002.

Zander, R., Mahieu, E., Demoulin, P., Servais, C., and Melen, F.: Long-term evolution of the loading of $\mathrm{CH}_{4}, \mathrm{~N}_{2} \mathrm{O}, \mathrm{CO}, \mathrm{CCl}_{2} \mathrm{~F}_{2}$, $\mathrm{CHClF}_{2}$, and $\mathrm{SF}_{6}$ above central Europe during the last 15 years, in: Non- $\mathrm{CO}_{2}$ Greenhouse Gases: Scientific Understanding, Control, and Implementation, Proc. 2nd International Symp., edited by: van Ham, J., Baede, A., Meyer, L., and Ybema, R., Kluwer Academic Publishers, Dordrecht, Noordwijkerhout, The Netherlands, 211-216, 2000.

Zimmermann, P. H., Feichter, J., Rath, H. K., Crutzen, P. J., and Weiss, W.: A global three-dimensional source-receptor model investigation using ${ }^{85} \mathrm{Kr}$, Atmos. Environ., 23, 25-35, 1989. 